\title{
Discrete element framework for modeling tertiary creep of concrete in tension and compression
}

\author{
Ioannis Boumakis ${ }^{1}$, Giovanni Di Luzio ${ }^{2}$, Marco Marcon ${ }^{1}$, Jan Vorel ${ }^{1,3}$, Roman \\ Wan-Wendner ${ }^{1}$ \\ 1 Christian Doppler Laboratory, University of Natural Resources and Life Sciences, \\ Vienna, Austria \\ 2 Dept. of Civil and Environmental Engineering, Politecnico di Milano, Milan, Italy \\ 3 Dept. of Mechanics, Faculty of Civil Engineering, Czech Technical University in \\ Pragure, Czech Republic
}

\begin{abstract}
In this contribution, a computational framework for the analysis of tertiary concrete creep is presented, combining a discrete element framework with linear visco-elasticity and rate-dependency of crack opening. The well-established Lattice Discrete Particle Model (LDPM) serves as constitutive model. Aging visco-elasticity is implemented based on the Micro-Prestress-Solidification (MPS) theory, linking the mechanical response to the underlying physical and chemical processes of hydration, heat transfer and moisture transport through a multi-physics approach. The numerical framework is calibrated on literature data, which include tensile and compressive creep tests, and tests at various loading rates. Afterwards, the framework is validated on time-to-failure tests, both for flexure and compression. It is shown that the numerical framework is capable of predicting the time-dependent evolution of concrete creep deformations in the primary, secondary but also tertiary domains, including very accurate estimates of times to failure. Finally, a predictive numerical study on the time-to-failure response is presented for load levels that can not be experimentally tested, showing a deviation from the simple linear trend that is
\end{abstract}

\footnotetext{
*Roman Wan-Wendner

Email address: roman.wendner@boku.ac.at (Ioannis Boumakis ${ }^{1}$, Giovanni Di Luzio ${ }^{2}$, Marco Marcon ${ }^{1}$, Jan Vorel ${ }^{1,3}$, Roman Wan-Wendner ${ }^{1}$ )
} 
commonly assumed. Ultimately, two alternative functions for time-to-failure curves are proposed that are mechanically justified and in good agreement with both, experimental data and numerical simulations.

Keywords: creep, concrete, tertiary creep, time to failure, rate effect

\section{Introduction}

Concrete creep is a well-known phenomenon that may influence the lifetime of concrete structures. In the concrete construction industry it is typically assumed that creep is a process that leads to increasing deformations with-

5 out significant damage development. Consequences for structural design are, thus, mostly limited to serviceability considerations, i.e. checks of deformations. Potential positive effects resulting from local stress redistributions are mostly neglected. Under these assumptions, the theory of linear visco-elasticity is typically sufficient for the calculation of creep deformations in standard design situations. The necessary and usually sufficient condition is a limitation of concrete stresses to less than $40 \%$ of the concrete compressive strength under the quasi-permanent load combination as required by Eurocode 2 [1] and $50 \%$ by ACI [2].

Nevertheless, situations exist in which concrete creep affects the ultimate limit state and the safety of structures. On the system level for example, concrete creep is a major source of continuously increasing pre-stress losses in pre-stressed and post-tensioned structures that not only lead to potentially excessive deflections, as e.g. observed for the KororBabeldaob bridge [3, 4], but are also associated with a significant reduction in shear capacity. On the material and component level, concrete creep may interact with existing damage and ultimately cause progressive failure due to stress redistributions that prompt further crack propagation. For moderately high load levels between about $40 \%$ and $65 \%$ this behavior is approximately accounted for by non-linear (stress-dependent) visco-elastic models [1].

However, a complete understanding of the creep mechanism under high load 
levels requires the detailed analysis of interactions between creep and crack propagation. Unlike the initial creep response that stabilizes with a decreasing creep rate (primary creep) followed by a phase with constant creep rate (secondary creep) the final stage, usually called tertiary creep, is characterized by so an exponential increase of the strain rate and results in failure.

Heretofore, various approaches have been introduced in order to model the tertiary creep of concrete. These approaches can be summarized as (a) ratedependent softening based on activation energy [5, 6, (b) coupling of a rheological model to a fictitious crack model [7, 8, 9, 10, (c) combination of a micromechanical model and a rheological model for softening and time-dependent behavior of concrete [11, and (d) coupling of a rheological model to a continuum-based constitutive law. For approach (d) various types of constitutive laws have been introduced: de Borst [12] proposed a combination of the smeared crack approach and plasticity; an isotropic damage law was used by Mazzotti and Savoia [13];

40 Bendoudjema et al. [14] utilized an elasto-plastic damage law; Rate-dependency of the damage law can be found in Challamel et al. [15]; Rate-dependency in softening plasticity was introduced by Van Zijl et al. [16]; Di Luzio implemented a rate-dependent micro-plane based constitutive model [17].

In this work an approach similar to that adopted by Di Luzio [17] is used, 45 however transferred to a discrete element framework in which rate-dependent fracture and a rate-type creep model are coupled. The well-established Lattice Discrete Particle Model (LDPM) [18, 19] serves as mechanical constitutive model. Aging visco-elasticity is implemented based on the Micro-PrestressSolidification (MPS) theory [20, 21], which is able to link the mechanical response to the underlying physical and chemical processes of hydration, heat transfer and moisture transport through a multi-physics approach [22, 23].

In the present manuscript, after introducing the modeling framework, the model components are calibrated on literature data, which include tensile and compressive creep tests, and tests at various loading rates. Afterwards, the framework is validated on time-to-failure (TTF) tests, both for flexural and compressive creep failure. It is shown that the numerical framework is capable 
of predicting the time-dependent evolution of concrete creep deformations in the primary, secondary but also tertiary domains, including very accurate estimates of times to failure. Finally, a predictive numerical study on the time to failure response is presented for load levels that can not be experimentally tested. The results clearly show a deviation from the simple linear trend that is commonly assumed. Ultimately, two alternative functions for time-to-failure curves are proposed that are in good agreement with both, experiments and numerical simulations.

\section{Review of constitutive modeling framework}

In this section a numerical framework is presented that combines a discrete model for concrete with rate-dependent fracture and aging linear visco-elasticity into a powerful tool for the investigation of tertiary creep. The basis of the time-dependent mechanical analysis is a multi-physics model that simulates the chemical reactions of concrete, coupled with moisture transport and heat transfer in interaction with the environment. The solution of the coupled system of equations yields the basic physical and chemical quantities, namely hydration degree, humidity rate, and temperature rate, which drive thermal strains, hygral shrinkage and determine the evolution of material properties as well as the kinetics of concrete creep. The coupling between mechanical response and physical/ chemical processes of concrete at early age has already been used in some recent applications [24, 25, 26, 27, 28,

\subsection{Hydration and diffusion}

The coupled problem of chemical reactions - hydration of cement, and pozzolanic reactions - moisture transport and heat transfer is solved using the Hygro-Thermo-Chemical (HTC) model [22, 23. The reaction kinetics are formulated in terms of reaction degrees, that represent the progress of each chemical reaction, which are described by the respective chemical affinity [29, 30] and an Arrhenius type evolution. Coupling between chemical reactions and 
transport processes is achieved by combining the mass and enthalpy balance equations with Fick's and Fourier's laws, respectively, leading to a system of partial differential equations with only two state variables - the temperature $T$ and the pore relative humidity $h$ :

$$
\nabla \cdot\left(D_{h} \nabla h\right)-\frac{\partial w_{e}}{\partial h} \frac{\partial h}{\partial t}-\frac{\partial w_{e}}{\partial \alpha_{c}} \dot{\alpha}_{c}-\frac{\partial w_{e}}{\partial \alpha_{s}} \dot{\alpha}_{s}-\dot{w}_{n}=0
$$

where $D_{h}$ the moisture permeability of concrete, $w_{e}$, and $w_{n}$ the evaporable and non-evaporable water, respectively, and $\alpha_{c}$ and $\alpha_{s}$ the degree of cement hydration and silica fume, as well as pozzolanic reaction.

$$
\nabla \cdot\left(k_{t} \nabla T\right)-\rho c_{t} \frac{\partial T}{\partial t}+\dot{\alpha}_{c} c \tilde{Q}_{c}^{\infty}+\dot{\alpha}_{s} s \tilde{Q}_{s}^{\infty}=0
$$

where $k_{t}$ heat conduction coefficient, $\rho$ density, $c_{t}$ isobaric heat capacity, $c$ and $s$ cement and silica fume content, and $\tilde{Q}_{c}^{\infty}$, and $\tilde{Q}_{s}^{\infty}$ enthalpies of hydration and silica fume reaction, respectively.

The rate of the cement hydration degree, $\dot{\alpha}_{c}$, is given in Eq. 3 and follows an Arrhenius type evolution expressed by the exponential term with $E_{a c}$ the activation energy, and $R$ the gas constant. The other terms express the normalized chemical affinity with $A_{c 1}, A_{c 2}$, and $\eta_{c}$ material parameters which define the reaction kinetics, while $\alpha_{c}^{\infty}$ is the theoretical asymptotic degree of hydration. The first term that contains the relative humidity $h$ expresses the delay of the hydration reaction when the water supply becomes low, as proposed in [30, 31.

$$
\dot{\alpha}_{c}=\frac{A_{c 1}}{1+(5.5-5.5 h)^{4}}\left(\frac{A_{c 2}}{\alpha_{c}^{\infty}}+\alpha_{c}\right)\left(\alpha_{c}^{\infty}-\alpha_{c}\right) e^{-\eta_{c} \alpha_{c} / \alpha_{c}^{\infty}} \cdot e^{-E_{a c} / R T}
$$

The HTC model solves the heat transport problem by formulating only one mechanism of heat transfer, i.e. the linear heat conduction that is expressed by the term $\nabla \cdot\left(k_{t} \nabla T\right)$ in Eq. 2. The other two heat transfer mechanisms, 85 surface heat radiation and heat convection, are neglected. This approximation is sufficient since in the inner part of concrete the main mechanism of heat transfer is conduction.

For moisture transport (Eq. 1) a non-linear water diffusion process is assumed under isothermal conditions. Due to a lack of experimental data on 
differences between wetting and drying isotherms no distinction is made hereafter. However, for most of the applications, including the current study, this approximation suffices because no wet/ dry cycles have to be considered.

\subsection{Mechanical model}

In this work, a discrete concrete model, the Lattice Discrete Particle Model

polyhedral cells interact through triangular facets and a lattice system made up of the segments that connect the sphere centers. The behavior of the material is represented by vectorial constitutive equations of the form, $\sigma=f(\epsilon)$ with the stress vector, $\sigma=\left[t_{N} t_{M} t_{L}\right]^{T}$, and the strain vector, $\epsilon$.

LDPM uses rigid body kinematics to describe the deformation of the particle system and the displacement jump, $\llbracket \mathbf{u}_{C} \rrbracket$, at the centroid of each facet is used to define measures of strain as

$$
e_{N}=\frac{\mathbf{n}^{\mathrm{T}} \llbracket \mathbf{u}_{C} \rrbracket}{\ell} \quad e_{L}=\frac{\mathbf{l}^{\mathrm{T}} \llbracket \mathbf{u}_{C} \rrbracket}{\ell} \quad e_{M}=\frac{\mathbf{m}^{\mathrm{T}} \llbracket \mathbf{u}_{C} \rrbracket}{\ell}
$$

with $\ell$ the distance between the particles, and $\mathbf{n}, \mathbf{l}, \mathbf{m}$, are the vectors defining a vectorial basis, i.e. the local reference system of each facet, and $\epsilon=\left[e_{N} e_{M} e_{L}\right]^{T}$ stands for the facet strain vector. The strains of Eq. 4 have been found to be the projections of the strain tensor of continuum mechanics into the local reference system, [36, 37, 38. In the elastic domain the vectorial constitutive relation 
between stress and strain components are

$$
t_{N}=E_{N} e_{N}^{*} \quad t_{M}=E_{T} e_{M}^{*} \quad t_{L}=E_{T} e_{L}^{*},
$$

where $e_{N}^{*}, e_{M}^{*}$, and $e_{L}^{*}$ are the instantaneous plus mechanical deformations (see Eq. 8), $E_{N}=E_{0}$, and $E_{T}=\alpha E_{0}$, with $E_{0}$ the effective normal modulus, $\alpha=(1-4 \nu) /(1+\nu)$ the shear-normal coupling parameter, and $\nu$ the Poisson's ratio. The strain components can be corrected by eigenstrains resulting from different phenomena, like thermal expansion, shrinkage, or expansive chemical reactions such as e.g. alcali-silica reaction. Due to strain additivity viscoelasticity problems can be represented by elasticity problems in which the creep strains are introduced as additional eigenstrains. A more detail discussion of the viscoelastic problem follows in section 2.3. The LDPM formulation explicitly models fracture and cohesion, compaction and pore collapse, and internal friction. For tensile loading, $e_{N}^{*}>0$ fracturing behavior can be formulated through effective strain $\epsilon$ and effective stress $\sigma$, with

$$
\epsilon=\sqrt{e_{N}^{* 2}+\alpha\left(e_{M}^{* 2}+e_{L}^{* 2}\right)}, \sigma=\sqrt{\sigma_{N}^{2}+\alpha\left(\sigma_{M}^{2}+\sigma_{L}^{2}\right)}
$$

The effective stress is incrementally elastic obeying the inequality $0 \leq \sigma \leq$ $\sigma_{b}(e, \omega)$, with $\tan (\omega)=e_{N}^{*} / \sqrt{\alpha} e_{T}^{*}=t_{N} \sqrt{\alpha} / t_{T}$, and $H_{0}(\omega)=H_{t}(2 \omega / \pi)^{n_{t}}$, is the post peak softening modulus, with $H_{t}$ the softening modulus in pure tension ( $\omega=\pi / 2)$ expressed as $H_{t}=2 E_{0} /\left(\ell_{t} / \ell-1\right), \ell=$ the length of the tetrahedron edge, and $\ell_{t}=$ the tensile characteristic length. The stress boundary is given by

$$
\sigma_{b t}=\sigma_{0}(\omega) \exp \left[-H_{0}(\omega)\left\langle\epsilon-\epsilon_{0}(\omega)\right\rangle / \sigma_{0}(\omega)\right]
$$
$\sigma$ reaches the elastic limit.

\subsection{LDPM coupling with HTC model}

Although the phenomena of concrete creep and shrinkage are known for many decades now, the actual underlying mechanisms are still not fully under- 
community uses mostly semi-empirical models 2, 39, 40, 41, 42, 43. Usually their calibration is performed on experimental data. Afterwards they predict the time evolution of creep and shrinkage on a cross-sectional level, and in accumulated form. Various material properties, e.g compressive strength, water to cement ratio, cement content, and environmental conditions, among others, act as input variables of the models. In spite of all efforts the model predictions are often quite far from the measured response [41, 44]. Thus, a more refined modeling approach must be employed for more demanding problems - a local point-wise model formulated in a rate-type form which is able to combine the different physical and chemical mechanisms.

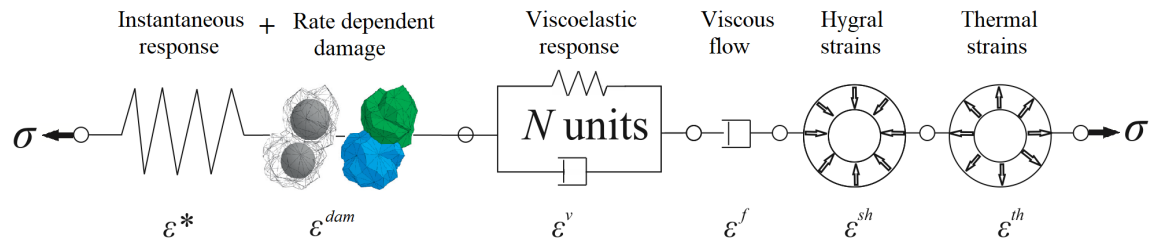

Figure 1: Rheological model for coupling

In this work, creep and shrinkage are modeled in a rate-type form based on the Micro-Prestress-Solidification Theory (MPS) first proposed by Bažant and co-workers [20, 21]. The model following the rheological representation of Figure 1 splits the total strain rate, $\dot{\epsilon}_{t o t}$, into different strain rates that describe different physical mechanisms. These are an instantaneous response, $\dot{\epsilon}^{*}$ described by a non-aging spring plus the strain rate due to damage, $\epsilon_{d a m}$, which are determined from LDPM, viscoelastic response, $\dot{\epsilon}_{v}$, represented by a non-aging Kelvin chain with typically ten elements in combination with an aging function formulated in terms of reaction degree [45, 46]. Additionally, the model accounts for the pure viscous flow, $\dot{\epsilon}_{f}$, using an aging dashpot calculated from the Micro-Prestress theory [45, 46]. Furthermore, the hygral, $\dot{\epsilon}_{s h}$, and thermal, $\dot{\epsilon}_{t h}$, strain rates are added. The total strain rate is imposed as the summation 
of the individual strain rates:

$$
\dot{\epsilon}_{t o t}=\dot{\epsilon}^{*}+\dot{\epsilon}_{v}+\dot{\epsilon}_{f}+\dot{\epsilon}_{s h}+\dot{\epsilon}_{t h}+\dot{\epsilon}_{d a m}
$$

Numerically, the solution of the multi-physics model and the mechanical model are coupled in one-way only so that the parameters of the mechanical model and the imposed eigenstrain increments are updated to reflect the evolving hydration degree, temperature and relative humidity fields. However, the effects of damage or deformation state on the transport processes are not accounted for. In this work the time-dependent evolution of strength and fracture are neglected, while aging of the visco-elastic response is accounted for by the MPS theory. Aging fracture properties could have been introduced following the work of Wan et al. for UHPC 47, 48, and Wendner et al. 49. However, for this investigation the approximation of constant mechanical properties is sufficient considering the relatively short duration of the tests (the failure times were less than 1 day) compared to the concrete age of 4 months and 56 days, respectively.

In general, visco-elasticity can be described by a compliance function $J\left(t, t^{\prime}\right)=$ $\epsilon / \sigma$, where $t$ the age of concrete and $t^{\prime}$ the age at loading, $\epsilon$ the resulting strain when a constant unit stress $\sigma=1 \mathrm{MPa}$ is applied. As shown by Bažant 50 for the general three-dimensional case and under the assumption of a time-invariant Poisson's ratio $\nu$ the compliance function can be expressed as:

$$
J\left(t, t^{\prime}\right)=\xi_{1}+C\left(t, t^{\prime}\right)
$$

where $\xi_{1}=1 / E_{0}$ the instantaneous elastic compliance, and $C\left(t, t^{\prime}\right)$ is the creep compliance function. The parameter $\xi_{1}$ is used for the calculation of the instantaneous strain $\epsilon^{*}$, since $\dot{\epsilon}^{*}=\xi_{1} \mathbf{G} \dot{\sigma}$, where $\sigma=$ the applied stress, and $\mathbf{G}$ is a constant matrix, under the assumption that the viscoelastic process does not vary the material isotropy ( $\nu=$ constant). Therefore $\mathbf{G}$ can be expressed as

$$
\mathbf{G}=\left(\begin{array}{ccc}
1 & 0 & 0 \\
0 & 1 / \alpha & 0 \\
0 & 0 & 1 / \alpha
\end{array}\right)
$$


where $\alpha=$ the shear-normal coupling parameter which is related to Poisson's ratio $\nu$ as summarized in section 2.2. It is easily understood that the relations of Eq. 5 can be also expressed as $\epsilon^{*}=1 / E_{0} \mathbf{G} \sigma$.

Any non-aging creep compliance function $C\left(t, t^{\prime}\right)$ can be represented by a non-aging Kelvin chain expressed as Dirichlet series with $N$ elements as

$$
C\left(t, t^{\prime}\right)=\sum_{\mu=1}^{N} A_{\mu}\left[1-\exp \left(-\left(t-t^{\prime}\right) / \tau_{\mu}\right)\right]
$$

where $E_{\mu}$ the elastic moduli of the $\mu$ th unit of the chain, $\tau_{\mu}$ the retardation time of the $\mu$ th unit of the chain, and $A_{\mu}=1 / E_{\mu}$ the strain increment during time equal to $\tau_{\mu}$. In general, the identification of chain parameters directly from creep data is a ill-posed problem and leads to non-unique chain properties. Through the introduction of a continuous retardation spectrum as discussed subsequently this problem is overcome by linking the individual dash pot viscosities and spring stiffnesses to a significantly lower number of parameters defining the spectrum.

The most efficient and accurate way to evaluate the values of $A_{\mu}$ is by assuming an infinite, i.e. continuous, Kelvin chain with infinitely close retardation times. Following this the creep compliance function can be expressed with the help of a continuous retardation spectrum $L(\tau)$ as:

$$
C\left(t, t^{\prime}\right)=\int_{-\infty}^{+\infty} L(\tau)\left[1-\exp \left(-\left(t-t^{\prime}\right) / \tau\right)\right] d(\ln \tau)
$$

and the retardation spectrum can be derived as

$$
L(\tau)=-\lim _{k \rightarrow \infty} \frac{(-k \tau)^{k}}{(k-1) !} C^{(k)} k \tau
$$

where $k$ is the order of the retardation spectrum. It can be assumed that the creep compliance follows a logarithmic - power law function, expressed by

$$
C\left(t, t^{\prime}\right)=\xi_{2} \ln \left[1+\left(\frac{t-t^{\prime}}{\lambda_{0}}\right)^{n}\right]
$$

with $\xi_{2}, \lambda_{0}=1$ day, $n=0.1$ material parameters, and $t-t^{\prime}$ is the duration since load application $t^{\prime}$. This functional form has been selected as a compromise between the power-law shape of short term creep and the logarithmic evolution 
of long-term creep. Based on the chosen functional form of the creep compliance the latter can be expressed for a retardation spectrum of order 3 as

$$
\begin{array}{r}
L(\tau)=\left[\frac{-2 n^{2}(3 \tau)^{2 n-3}\left(n-1-(3 \tau)^{n}\right)}{\left(1+(3 \tau)^{n}\right)^{3}}\right] \frac{(3 \tau)^{3}}{2} \xi_{2} \\
+\left[\frac{n(n-2)(3 \tau)^{n-3}\left[n-1-(3 \tau)^{n}\right]-n^{2}(3 \tau)^{2 n-3}}{\left[1+(3 \tau)^{n}\right]^{2}} \frac{(3 \tau)^{3}}{2} \xi_{2}\right]
\end{array}
$$

In order to compute numerically the integral of Eq. 12 the continuous spectrum has to be discretized and then approximated by a sum. It is most convenient to space the retardation times $\tau_{\mu}$ equidistantly in logarithmic time. Based on previous studies by Bažant and co-workers a spacing between retardation times of $\Delta\left(\log \tau_{\mu}\right)=\log (10)$ results in a sufficiently accurate approximation. Then the total creep compliance can be approximated as a finite sum with the contributions $A_{\mu}=L\left(\tau_{\mu}\right) \ln 10 \Delta\left(\log \tau_{\mu}\right)$ of $N$ Kelvin chain elements:

$$
C\left(t, t^{\prime}\right)=A_{0}+\sum_{\mu=1}^{N} A_{\mu}\left(1-\exp \left(-\left(t-t^{\prime}\right) / \tau_{\mu}\right)\right)
$$

It is important to also account for the area under the continuous spectrum up to the shortest retardation time $\tau_{1}$ considered. This area under the tail is included in the constant $A_{0}$, see Figure 2. As previously shown [51] the theoretical value of the constant $A_{0}$ is given by the integral $A_{0}=\int_{-\infty}^{\tau_{0}} L(\tau) d \tau$, where the upper integration limit $\tau_{0}$ can be determined for a spacing of $\log (10)$ as $\tau_{0}=\tau_{1} / \sqrt{10}$, where $\tau_{1}=$ the first retardation time of the Kelvin chain.

However, a more preferable computational method of the constant $A_{0}$ is through the minimization of the error of the series of Eq. 16 compared to it's theoretical value[51] as

$$
A_{0}=\frac{1}{t-t^{\prime}} \int_{0}^{t-t^{\prime}}\left[C\left(t, t^{\prime}\right)-\sum_{\mu=1}^{N} A_{\mu}\left(1-\exp \left(-\left(t-t^{\prime}\right) / \tau_{\mu}\right)\right)\right] d\left(t-t^{\prime}\right)
$$

This approach has the advantage that the accumulated discretization error can be corrected for based on the time period of interest. For this investigation an upper integration limit of $t-t^{\prime}=365$ days is used as compromise between 


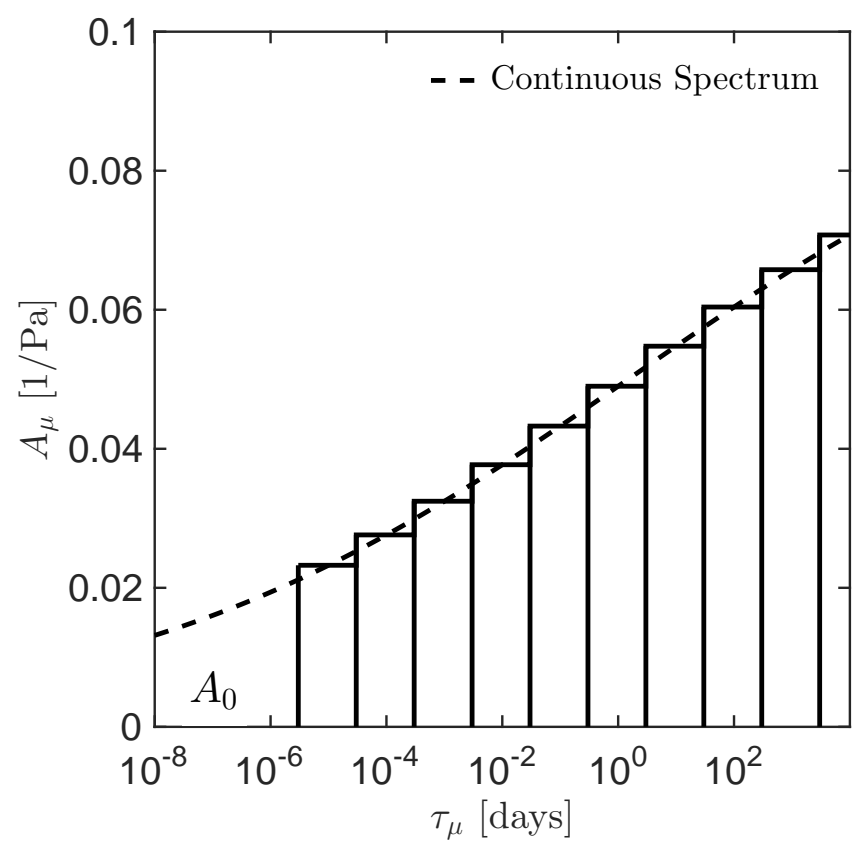

Figure 2: Discretization of the continuous retardation spectrum

short loading durations and the multi-decade behavior. The integral is most efficiently evaluated using the trapezoidal rule with logarithmically spaced time steps. In Table 1 the calculated $A_{0}$ values are reported for three different values of $\tau_{1}$, three upper integration limits, and for $\xi_{2}=1$. As it can be seen the integration limit doesn't have a significant effect on the calculated values. However, the values of $A_{0}$ sensitive to the choice of the first retardation time $\tau_{1}$.

\begin{tabular}{llll}
\hline$\tau_{1}[$ days $]$ & $10^{-5}$ & $10^{-4}$ & $10^{-3}$ \\
\hline$A_{0}\left(t-t^{\prime}=365\right.$ days $)\left[\mathrm{Pa}^{-1}\right]$ & 0.226 & 0.279 & 0.343 \\
$A_{0}\left(t-t^{\prime}=3,650\right.$ days $)\left[\mathrm{Pa}^{-1}\right]$ & 0.228 & 0.279 & 0.342 \\
$A_{0}\left(t-t^{\prime}=20,000\right.$ days $)\left[\mathrm{Pa}^{-1}\right]$ & 0.244 & 0.281 & 0.343 \\
\hline
\end{tabular}

Table 1: Values of $A_{0}$ for different first retardation times $\tau_{1}$ of the Kelvin chain and different upper integration limits

Assuming that the creep response of fully hydrated cement gel is an in- 
trinsic material property the problem of macroscopic aging visco-elasticity can be converted into non-aging visco-elasticity of the fully hydrated cement gel and an aging function predicting the amount of gel already formed. Thus, the creep microstrain rate of the non-aging cement gel under constant stress can be expressed with the help of Eq. 16 as:

$$
\dot{\gamma}=\sigma\left[A_{0}+\sum_{\mu=1}^{N} A_{\mu}\left(1-\exp \left(-\left(t-t^{\prime}\right) / \tau_{\mu}\right)\right)\right]
$$

The aging viscoelastic response of concrete is obtained by introducing an aging function expressed as

$$
\dot{\epsilon}_{v}=\frac{1}{v\left(\alpha_{c}\right)} \cdot \dot{\gamma}
$$

where $v\left(\alpha_{c}\right)=$ is the function that approximates the amount of hydrated cement gel which can be calculated as $v\left(\alpha_{c}\right)=\left(\alpha_{c} / \alpha_{c}^{\infty}\right)^{n_{a}}$, in which $\alpha_{c}$ is the hydration degree and the exponent $n_{a}$ can be calibrated using short term creep data for different loading ages.

Due to the introduction of function $v\left(\alpha_{c}\right)$ any macroscopic viscoelastic strain $\epsilon_{v}$ can only be partially recovered after unloading, although the micro-strain of 180 the cement gel $\gamma$ can be fully recovered. Furthermore, in this formulation time is replaced with the reduced time $t_{r}(t)=\int_{0}^{t} \psi_{s}(\tau) d \tau$ capturing temperature and relative humidity effect on the microscale creep with the activation energy $Q_{v} / R \approx 3000 \mathrm{~K}$, and the function $\psi_{s}(t)=\left[0.1+0.9 h^{2}\right] \exp \left[Q_{v} / R\left(1 / T_{0}-1 / T\right)\right]$. Thus, the creep microcompliance can be expressed as $C\left(t_{r}(t), t^{\prime}\right)$.

Finally the plastic creep strain rate, $\dot{\epsilon}^{f}$, i.e. the viscous flow rate, that originates in the slippage between adsorbed water layers can be described by the Micro-Prestress theory. The source of this creep deformations lies in the relaxation of disjoining pressures and the rupture of atomic bonds. Bažant [20] proposed to formulate the viscous flow in terms of microprestress $S$, which describes the stress among the bonds of the gel pores and is expressed by the differential equation

$$
\dot{S}+\psi_{s}(t) \kappa_{0} S^{2}=\kappa_{1}|\dot{T} \ln (h)+T \dot{h} / h|
$$


with $\kappa_{0}, \kappa_{1}$ material parameters, and $\psi_{s}(t)$ the already introduced function of reduced time. Thus, the viscous strain rate is given by

$$
\dot{\epsilon}_{f}=\xi_{4} \kappa_{0} S \psi_{s}(t) \mathbf{G} \dot{\sigma}
$$

where $\xi_{4}=$ material parameter that has to be calibrated. Finally, the hygral and thermal strain rates of Eq. 8 can be assumed to be proportional to the humidity and temperature rates, respectively,

$$
\epsilon_{s h}=\alpha_{s h} \dot{h}
$$

where $\alpha_{s h}$ is the shrinkage coefficient, and $\alpha_{T}$ is the coefficient of thermal expansion.

$$
\epsilon_{T}=\alpha_{T} \dot{T}
$$

\subsection{Rate effect}

The change of loading rate has a direct effect on the mechanical properties of concrete, as it has been shown by many authors [52, 53, 54, 55, 56, 57, 58. This variation can be explained by three main mechanisms: (1) the creep of the material, (2) rate effect on the bond rupture, and (3) the effect of inertia in the crack propagation. For quasi-static tests, typically the loading rate $\dot{\epsilon}$ lies in between $10^{-7}$ and $10^{-3} \mathrm{~s}^{-1}$ [59], and whithin this strain rate range, the first two mechanisms mentioned above are dominant. Therefore, except the creep rate, also the rate dependency of the crack opening has to be taken into account. The rate effect can be modeled under the concept of a rate dependence on the fracture process 60. In general it can be accepted that fracture is the consequence of the rupture of atomic or molecular bonds, and that this breakage arises due to a thermal activation of the bonds.

Bažant 61] has formulated the cohesive crack model taking into account the aforementioned mechanism, in which the cohesive crack model is transformed in a time-dependent process characterized by an activation energy. The Maxwell-Boltzmann distribution describes statistically the thermal energies of 
the vibrating atoms or molecules in a solid material with the functional form:

$$
f=k_{b} \exp (-U / R T)
$$

with $f$ the frequency of particles having a potential energy of $U, k_{b}$ is a constant, $R$ the gas constant and $T$ the temperature. The vibration of the

205 molecules or atoms implies a maximum value, $Q$, of the potential energy, which physically represents the barrier of energy that a particle has to exceed in order to break a bond. In case of stress applications, $\sigma_{a}$, the potential energy is varying among $U \pm r_{a} \cdot \sigma_{a}$, with $r_{a}$ the distance from the equilibrium position to the position of maximum energy, i.e. the displacement caused by stress, and thus the product $r_{a} \cdot \sigma_{a}$ expresses the work of the latter. By denoting $f_{1}$ and $f_{2}$ the frequencies of the varied potential energies $U_{1,2}$, the rate of crack opening $\dot{w}$ can be taken as their difference with the proportionality constant $k_{f}$ :

$$
\dot{w}=k_{f}\left(f_{2}-f_{1}\right)
$$

By substituting $U_{1,2} \pm r_{a} \cdot \sigma_{a}$ in Eq. 24 and then the respective results in Eq. 25 . the rate of crack opening can be expressed as:

$$
\dot{w}=2 k_{b} k_{f} \sinh \left(r_{a} \sigma_{a} / R T\right) \exp (-Q / R T)
$$

which for constant temperature, and under the assumption of proportionality $\sigma_{a} \propto \sigma-\phi(w)$ with the cohesive crack model, yields

$$
\sigma(w, \dot{w})=\left[1+C_{1} \sinh ^{-1}\left(\dot{w} / C_{0}\right)\right] \phi(w)
$$

with $C_{0}=2 k_{b} k_{f} \exp \left(-Q / R T_{0}\right)$ and $C_{1}$ are material constants.

The above concept has been implemented in LDPM [59] by scaling the stressstrain boundary, defined in Eq. 7 by the function $F(\dot{\epsilon})$ as

$$
F(\dot{\epsilon})=1+C_{1} \sinh ^{-1}\left(\dot{\epsilon} /\left(C_{0} \ell_{c h}\right)\right.
$$




\section{Numerical Analysis}

215

3.1. Experimental data

The discussed computational framework is evaluated using data from two different contributions found in the literature. The two specific research works have been selected out of the very few available experimental investigations of time-dependent fracture as they reflect different types of tests. In the work 220 of Rüsch 62, the sustained loading was applied in compression, while Zhou 63. performed bending time-to-failure tests on notched and unnotched beams in a three point bending configurations, and creep relaxation tests on notched cylinders under tensile loading.

\subsection{Zhou data}

Zhou performed tests on concrete with cement content, $c=420 \mathrm{~kg} / \mathrm{m}^{3}$, water cement ratio, $w / c=0.55$, and aggregate to cement ratio of $a / c=3.81$. The size of aggregates used in the concrete mix design was within 0 and $4 \mathrm{~mm}$. The concrete had at 28-days a compressive strength of $f_{c 28}=38 \mathrm{MPa}$. All the tests, which comprised fracture tests in tension and bending, creep, and timeto-failure tests were performed at a concrete age of 4 months. The measured concrete properties were: tensile strength $f_{t}=2.8 \pm 0.2 \mathrm{MPa}$, fracture energy $G_{F}=82 \pm 9 \mathrm{Nm} / \mathrm{m}^{2}$, modulus of elasticity of $E=36 \pm 2 \mathrm{GPa}$, and characteristic length, indirectly obtained from the Hillerborg's equation [64, $\ell_{c h}=0.38 \mathrm{~m}$.

235 Table 2 shows the geometry and the number of specimens tested for the quasi-static tensile and fracture tests, the tensile relaxation tests, the rate tests and the time-to-failure creep tests.

In order to obtain the tensile strength, notched cylinders (NC) were tested under tensile loading. The NC had a notch width of $10 \mathrm{~mm}$ and a notch depth of $12 \mathrm{~mm}$ (see Figure 3 $\mathrm{p}$ ). Fracture properties were obtained from notched prisms (NP) with a support distance of $800 \mathrm{~mm}$ and notch depth of $50 \mathrm{~mm}$ (see Figure 3a). The data, which will be used for the creep calibration, was a 
relaxation tensile test on $\mathrm{NC}$ specimens. The specimens was loaded such that the notch opening reached $0.05 \mathrm{~mm}$ within 5 minutes. The notch opening was then kept constant for the next 60 minutes. Tests with four strain rates (see Figure 6a) were performed on NP specimens in order to evaluate the rate effect on the stress at peak. The notched prisms tested for rate effect had a support distance of $600 \mathrm{~mm}$ and a notch depth of $25 \mathrm{~mm}$. At last, time to failure creep tests were performed on two different geometries, notched prisms and unnotched prisms (UP) having different sizes. The notched prisms had the same geometry as those of the fracture energy tests and were tested with load levels in the range between $92 \%$ and $76 \%$ of the ultimate load of the related quasi-static test. The UP of size $320 x 50 x 50 \mathrm{~mm}$ were tested with a support distance of $300 \mathrm{~mm}$ and for a load range between $95 \%$ and $67 \%$ of the related ultimate load of the quasi-static test. No geometrical information could be retrieved for the other tests performed by Zhou [63, which were compression tests and elastic modulus determination tests.

\begin{tabular}{lllll}
\hline $\begin{array}{l}\text { Tests } \\
\text { type }\end{array}$ & ID & $\begin{array}{l}\text { Geometry } \\
\mathbf{m m}\end{array}$ & $\begin{array}{l}\text { No of } \\
\text { tests }\end{array}$ & $\begin{array}{l}\text { Measured } \\
\text { property }\end{array}$ \\
\hline Tension & NC & $64 \times 60$ & 5 & Tensile strength \\
Fracture & NP & $840 \times 100 \times 100$ & 6 & Fracture Energy \\
\hline Relaxation & NC & $64 \times 60$ & 6 & Creep (Relaxation) \\
\hline Rate & NP & $640 \times 50 \times 50$ & 14 & Stress at peak \\
\hline Creep & NP & $840 \times 100 \times 100$ & 14 & Creep rupture \\
Creep & UP & $320 \times 50 \times 50$ & 12 & Creep rupture \\
\hline
\end{tabular}

Table 2: Zhou data: Overview of the specimen geometry and number of tests

\subsection{Rüsch Data}

The concrete mix design used by Rüsch can be summarised as follows: ${ }_{260} c=337 \mathrm{~kg} / \mathrm{mm}^{3}, w / c=0.55$, and $a / c=5.47$. No information about the aggregate size distribution was provided. All the tests were performed at 


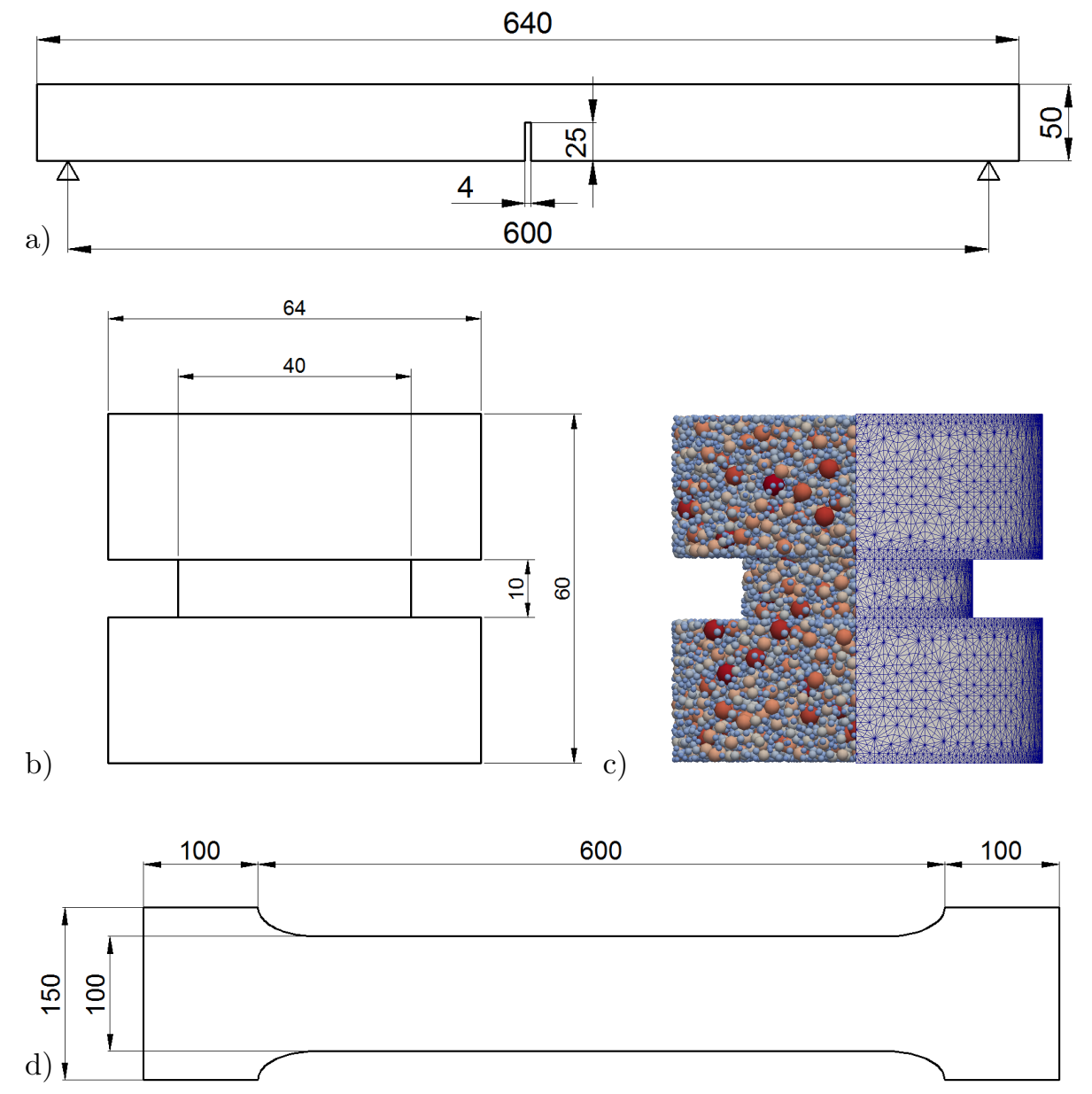

Figure 3: Specimens geometry: a) notched beam (Zhou), b) notched cylinder (Zhou) and c) related numerical model visualization, and d) geometry of the dog-bone-like specimen used by Rüsch for compressive strength and creep tests

a concrete age of 56 days. In order to obtain the compressive strength, two geometries were used: cylinders and prismatic dog-bone-type specimens. The geometry of the dog-bone-type specimens with a depth of $150 \mathrm{~mm}$ is shown in Figure $3 \mathrm{~d}$. The 56 days cylinder compressive strength was $20.68 \mathrm{MPa}$, while for the other geometry, the compressive strength was 34.47 MPa. The elastic modulus estimated from the compressive test results was $E \approx 41.3 \mathrm{GPa}$. 
Rate effect tests were performed on cylindrical specimens, while sustained load tests were carried out with the dog-bone-type geometry. The specimens were loaded at the different load levels (50 to $90 \%$ of the quasi-static compressive strength) in around $20 \mathrm{~min}$ and after that, the load was sustained. For load levels greater than $75 \%$ of the static compressive strength, failure was observed. The time to failure varied from a few minutes to 70 days.

\section{Models calibration}

The computational framework was calibrated twice using the considered experimental data presented in the previous section. It has to be noted that the studied effect of the rate can not be isolated from the other tests, i.e. the material properties are related to the loading rate and also creep contributes to deformations in all tests, especially the ones at low loading rates. The same applies to so-called quasi-static tests that also have a finite duration during which creep exists. Hence, for a more accurate calibration concrete creep tests at low load levels are required, for which the existence of damage can be excluded. Therefore, for the calibration of the static LDPM parameters creep and the loading rate dependence have to be active in the model. This study attempts to overcome this challenge by following an iterative procedure for calibration and optimization of the parameters. As a matter of fact after the first sequence of calibration, a second iteration took place including all the different aforementioned contributions, and after that, an optimization to the calibrated parameters, if necessary, was carried out.

Ideally, the calibration strategy follows the following sequence: (1) calibration of creep parameters on relaxation or creep data at low load levels without damage, (2) calibration of LDPM mesoscale static parameters on quasi-static data accounting for creep, (3) calibration of the rate effect parameters on experiments performed with different loading rates, (4) iterative improvement of calibrations to account for interactions of rate, creep and damage. The latter is especially important if only creep tests at moderate to high load levels 
are available and damage contributes to the observed response. In this case, the sequence of steps (1-2) may be inverted. A complete calibration procedure should also include the determination of the HTC parameters. Unfortunately, for the simulate concretes no information about the hydration kinetics is provided. Thus, the following parameters from literature [46] were adopted $A_{c 1}=$ $2.5 \cdot 10^{7}$ hours $^{-1} ; A_{c 2}=5 \cdot 10^{-3} ; \eta_{c}=7.5 ; c_{t}=1100 \mathrm{~J} / \mathrm{kg}^{o} \mathrm{C} ; Q_{c}^{\infty}=500 \mathrm{~J} / \mathrm{g} ;$ $D_{0}=10^{-7}[\mathrm{~kg} /(\mathrm{m} \mathrm{h})] ; D_{1}=2 \cdot 10^{-} 3[\mathrm{~kg} /(\mathrm{m} \mathrm{h})] ; n=4$.

In case of Zhou's data, aging effects are negligible since the tests were performed at a concrete age of approximately 4 months and the test durations were relatively short with a maximum of 0.12 days. Therefore, the hydration degree could be considered to be constant during the tests. Additionally, the specimens were kept sealed and, thus, also the pore humidity and the temperature can assumed to be constant. Only for the tests performed by Rüsch aging effects matter as the testing times reached 2 years of concrete age for the tests at lower load levels. Nevertheless, a reasonable estimation of the hydration reaction can be adopted based the behavior of a similar concrete 23 .

For the numerical simulations, three different realisations (seeds) of the particle placement were run for each configuration and test. Hence, the numerical scatter partially captures the experimental scatter resulting from the material heterogeneity. A more detailed discussion on the particles placement and the related influence on the numerical scatter can be found in 65,66 .

\subsection{LDPM parameter calibration}

In a first step the LDPM static parameters for both concretes are calibrated 320 as only creep data with moderately high load levels was available. For Zhou's data, the LDPM parameters are calibrated to match simultaneously the above mentioned experimental compressive strength and elastic modulus, and the experimental stress-notch opening curve of the notched cylinder under tensile loading. The compressive strength value was corrected with an aging function 67] to obtain an estimated value of strength at 4 month. In order to reproduce numerically the latter, a simulation was performed on a cubic specimen with an 
edge size of $100 \mathrm{~mm}$. The elastic modulus simulation was performed on a cylinder with sizes $150 \times 300 \mathrm{~mm}$. The experimental elastic modulus was matched by the initial slope of the stress-strain curve obtained numerically. The output of the tensile tests was a stress-notch opening curve (see Figure 4 ). The notch opening was experimentally measured by extensometers and extracted from the model through the displacement field. The experimental curves on fracture tests in bending were used as validation in a comparison with purely predictive simulations. Additionally following the proposed calibration sequence the entire process was repeated having the creep and rate effect active. In that case the mesoscale characteristic length had to be adjusted to $\ell_{t}=210 \mathrm{~mm}$ instead of $\ell_{t}=195$, which was it's initially calibrated value. As can be seen from the excellent agreement in Figure $4 \mathrm{~s}$, the calibrated model allowed to reproduce experiments which were not belonging to the part of data used for the parameters' calibration: the TPB simulation with a deflection rate of $5 \mu \mathrm{m} / \mathrm{s}$.
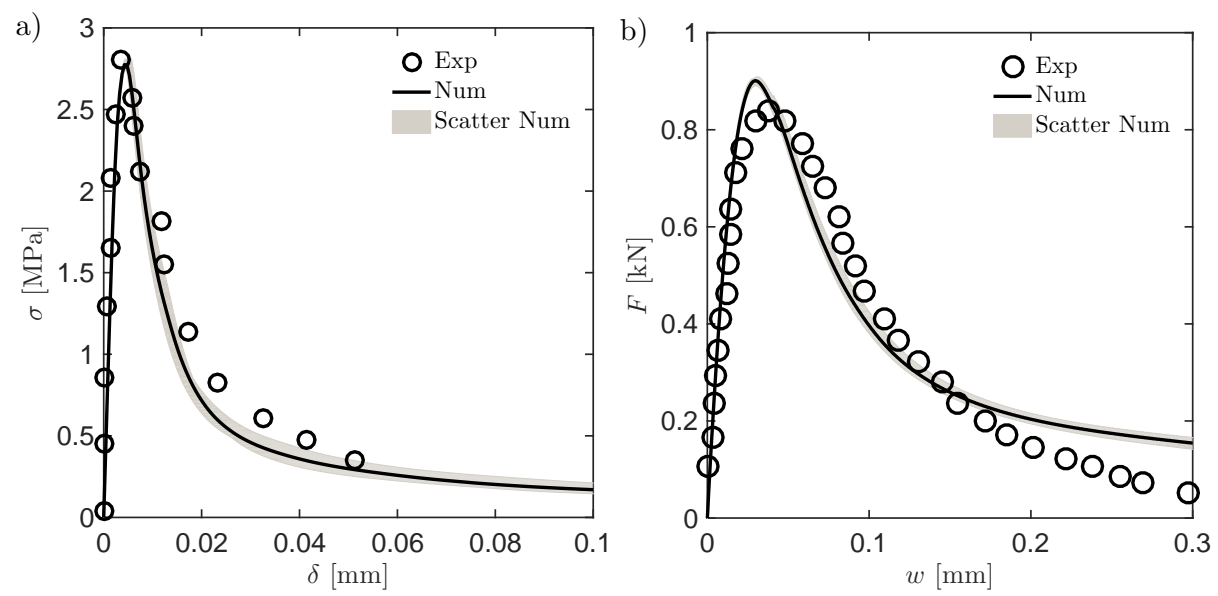

Figure 4: Calibration on notched cylinder a) and validation on three point bending test b) of the LDPM static parameters on Zhou's data.

A similar process was followed for the dataset of Rüsch. All the LDPM static parameters were calibrated on the two compressive tests aiming on matching the strength of both the geometries.

The mesoscale static LDPM parameters for both concretes can be found in 


\begin{tabular}{lllllllll}
\hline ID & $\begin{array}{l}\text { Age } \\
{[\text { days }]}\end{array}$ & $\begin{array}{l}E_{0} \\
{[\mathrm{GPa}]}\end{array}$ & $\begin{array}{l}\alpha \\
{[-]}\end{array}$ & $\begin{array}{l}\sigma_{t} \\
{[\mathrm{MPa}]}\end{array}$ & $\begin{array}{l}\ell_{t} \\
{[\mathrm{~mm}]}\end{array}$ & $\begin{array}{l}\sigma_{s} / \sigma_{t} \\
{[-]}\end{array}$ & $\begin{array}{l}\mu_{0} \\
{[-]}\end{array}$ & $\begin{array}{l}n \\
{[-]}\end{array}$ \\
\hline Zhou & 120 & 65 & 0.25 & 2.6 & 210 & 3 & 0.2 & 0.9 \\
Rüsch & 56 & 41.8 & 0.25 & 2.4 & 160 & 1.85 & 0.2 & 0.8 \\
\hline
\end{tabular}

Table 3: LDPM static parameters of both concretes

\subsection{Creep calibration}

After the calibration of the static parameters has been carried out, the calibration of the creep parameters is performed. Regarding Zhou's data 63, the relaxation tests on NC were numerically simulated. The model was loaded with the notch opening history reported for the experiment while the load relaxation was recorded. Figure 5 a shows the good agreement of the creep calibration with the experimental result. As a consequence of the prescribed displacement history, the load on the specimen reached about $75 \%$ of the maximum load obtained from the quasi-static tests. At this load level, micro-cracking surely happened and certainly influenced the relaxation process, which can be captured through the damage model on the level of facets.

For the second concrete, tested by Rüsch, the creep calibration was performed on the creep curve resulting from the specimen loaded at $50 \%$ of the related quasi-static compressive strength. In Figure 50, the best fitting simulation response is presented together with the experimental data. The simulated tests were performed under constant environmental conditions. Thus, the values $\kappa_{0}$, and $\kappa_{1}$ could not be calibrated. Following the approach adopted in [46] assumed values for similar concretes found in literature can be used. The calibrated creep parameters for both concretes are shown in Table 4.

\subsection{Rate effect calibration}

Finally, the rate effect parameters are calibrated using data from tests performed with different loading rates. For Zhou's concrete, three point bending 

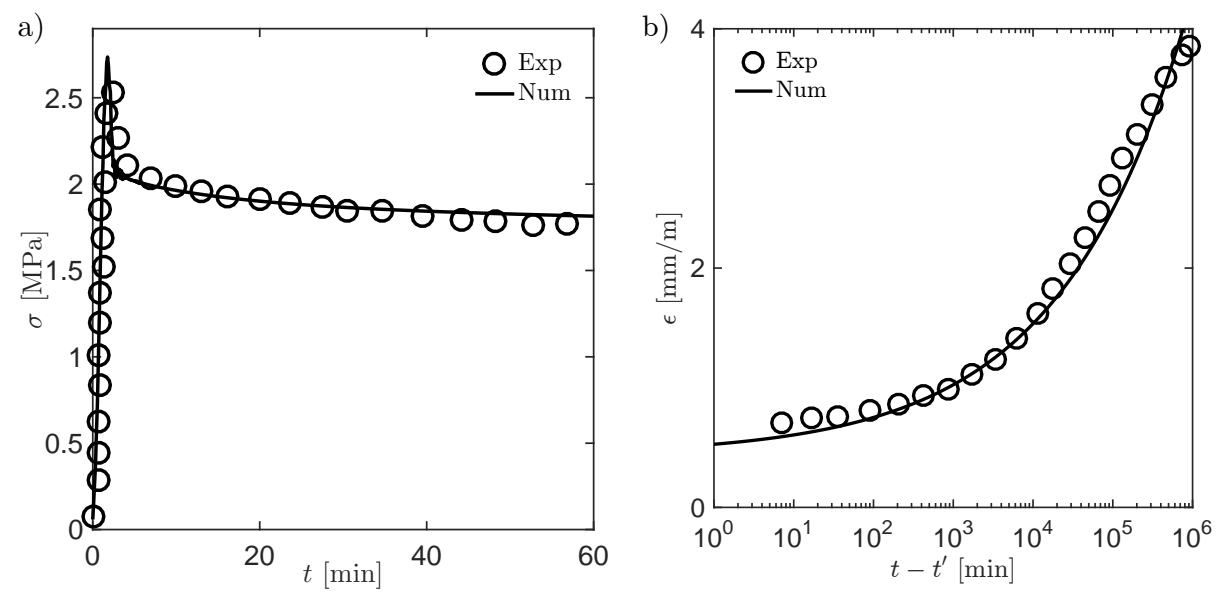

Figure 5: Calibration of the LDPM creep parameters: stress relaxation in Zhou's data a) and creep curve in Rüsch data b).

\begin{tabular}{llllll}
\hline ID & $\xi_{1}$ & $\xi_{2}$ & $\xi_{4}$ & $\kappa_{0}$ & $\kappa_{1}$ \\
& {$\left[\mathrm{MPa}^{-1}\right]$} & {$\left[\mathrm{MPa}^{-1}\right]$} & {$\left[\mathrm{MPa}^{-1}\right]$} & $\left.\left[\mathrm{MPa}^{2} \mathrm{ds}\right]\right]^{-1}$ & {$[\mathrm{MPa} / \mathrm{K}]$} \\
\hline Zhou & $6.7 \cdot 10^{-6}$ & $2.0 \cdot 10^{-5}$ & $2.8 \cdot 10^{-6}$ & $1.1 \cdot 10^{-15}$ & $7 \cdot 10^{6}$ \\
Rüsch & $7.3 \cdot 10^{-6}$ & $3.0 \cdot 10^{-5}$ & $2.5 \cdot 10^{-6}$ & $1.1 \cdot 10^{-15}$ & $7 \cdot 10^{6}$ \\
\hline
\end{tabular}

Table 4: Calibrated model parameters for creep and rate effect .

specimens were tested at the following loading rates $0.05,0.2,2$, and $50 \mu \mathrm{m} / \mathrm{s}$ and the corresponding reported times to peak ranged from 5 to $5000 \mathrm{sec}$. As previously mentioned, in Figure 3 the geometry of the tested notched prisms is shown, while Figure 6 a, shows the relative peak load (relative to the peak load of the highest rate) obtained for the different loading rates. The numerical model is capable of catching the increase in the peak load with increasing loading rate. Additionally, in Figure $7 \mathrm{a}$ and Figure $7 \mathrm{~b}$, the profiles of the maximum principal stresses at peak load are shown for the slowest and the highest loading rate, respectively. It is clear that higher loading rates lead to stresses distributed in a larger volume, which means higher energy dissipation. As also shown in [17] the concrete behavior becomes more brittle as the loading rate decreases associated 
with a shrinking fracture process zone (FPZ). Similar behavior has also been observed for thermally damaged concrete. The higher the temperature of the thermal treatment the more ductile is the material behavior leading to a longer FPZ 68, 69].
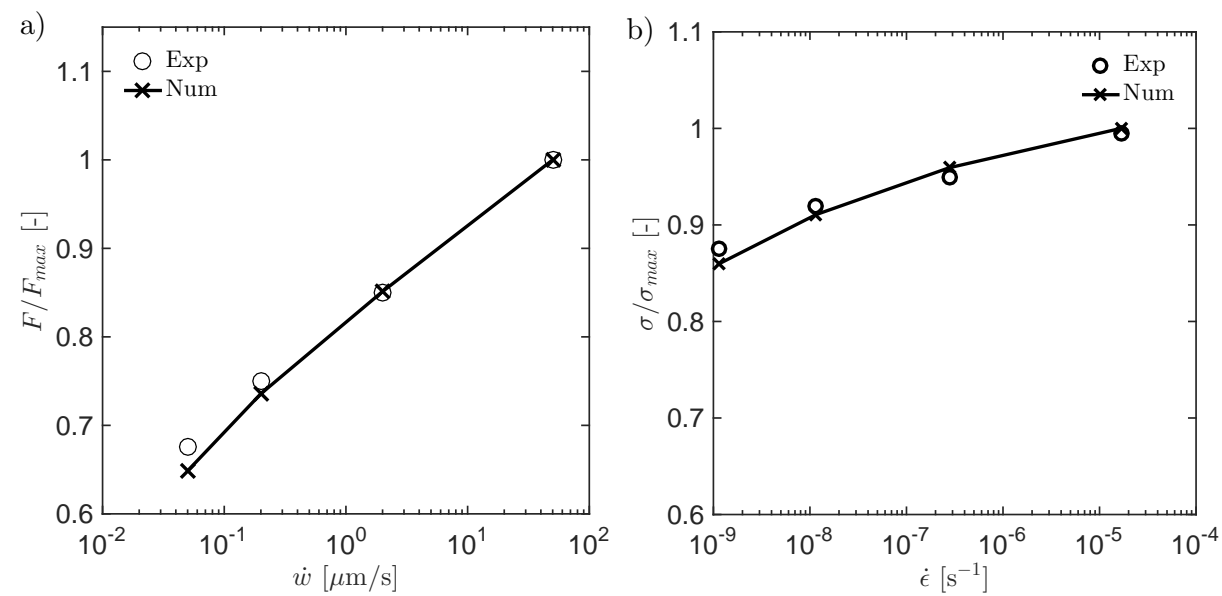

Figure 6: Calibration of the LDPM rate parameters in a) Zhou's data and b) Rüsch's data.

Similar to the Zhou rate calibration, the LDPM rate parameters were calibrated on Rüsch's experiments of different rates. The used specimen geometry was a cylinder with sizes $300 \times 150 \mathrm{~mm}$. Good agreement between the experimental results and the simulations can be seen in Figure 6b, in which the $\mathrm{Y}$ axes of the diagram is normalized with the stress at peak of the highest rate.

\section{Numerical simulations of Tertiary Creep and Time-to-Failure}

After the calibration of all three model components - quasi-static LDPM parameters, creep-model parameters, and rate-dependent fracture parameters the predictive quality of the computational framework is evaluated on several experimental data that have not been used for the calibration. In this step none of the model parameters is modified.

The validation is performed on time-to-failure curves for the flexural and compressive creep tests of Zhou and Rüsch, respectively. The failure times are 

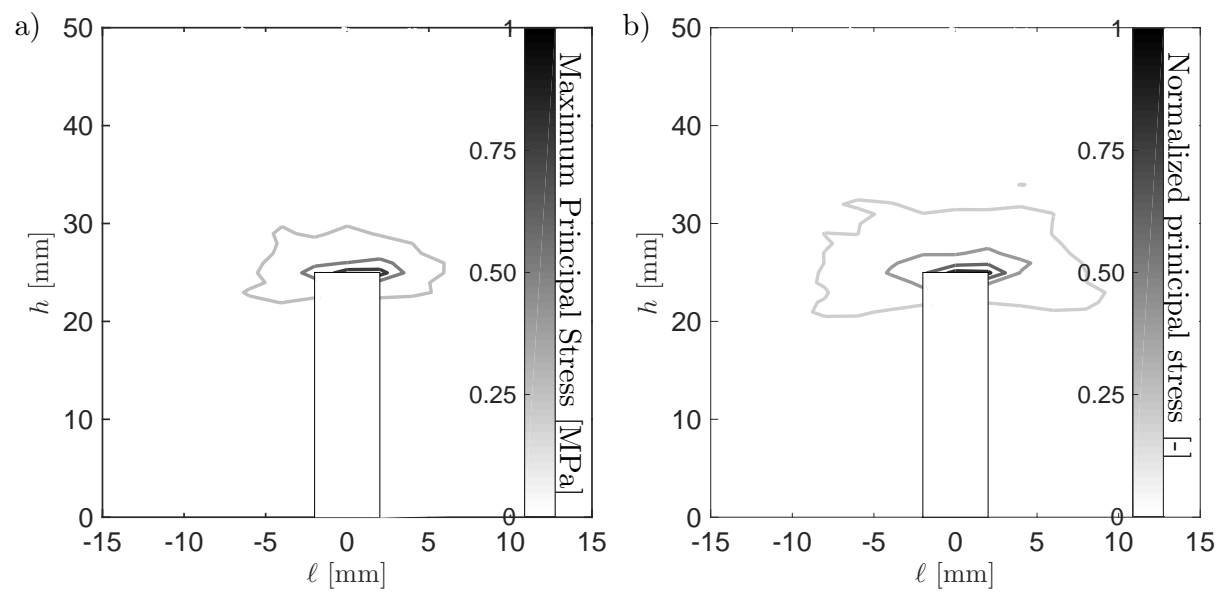

Figure 7: Maximum principal stresses normalized to their maximum value for the a) slowest and b) fastest of the rate tests of Zhou's data at the peak of the sustained load

determined as the time when the reaction forces on the supports are dropping significantly. It has to be noted that the discrete element simulations are run in an explicit framework which ensures a solution even after the specimen has broken, unlike the case of implicit algorithms, where failure is indicated only by a loss of convergence. The results clearly show that the behavior of concrete under moderate to high load levels can be predicted with a constitutive model that combines in series a linear creep model with a rate-dependent fracture model.

\subsection{Time to Failure}

First, simulations of sustained load tests on notched and unnotched beams (Zhou study 63]) are carried out. The load levels are selected to be the same as those from the experimental tests: $76 \%, 80 \%, 85 \%$, and $92 \%$ of the peak load $\left(P_{\max }\right)$ of the test with a deflection rate of $5 \mu \mathrm{m} / \mathrm{s}$.

In Section 4 the model calibration was presented based on the mean curves of three simulations each with different particle placements (seeds). Also for the time to failure simulations, three different realizations are run for each problem resulting in a numerical scatter in the obtained times to failure. The sustained 
load levels for the simulations are based on the mean peak values of the respective quasi-static simulations.
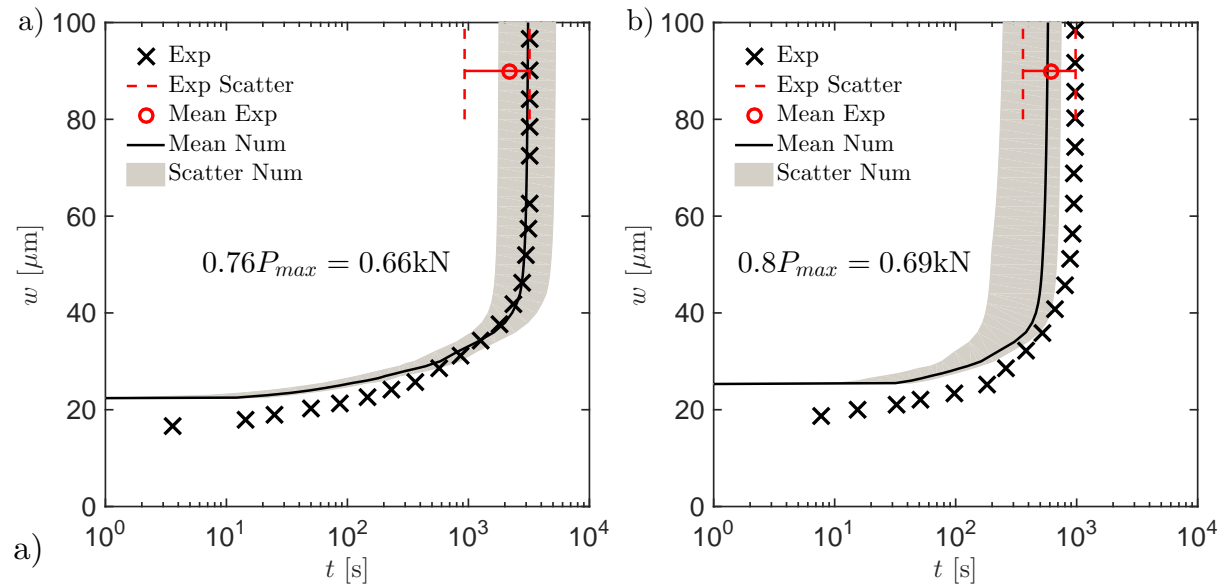

b)
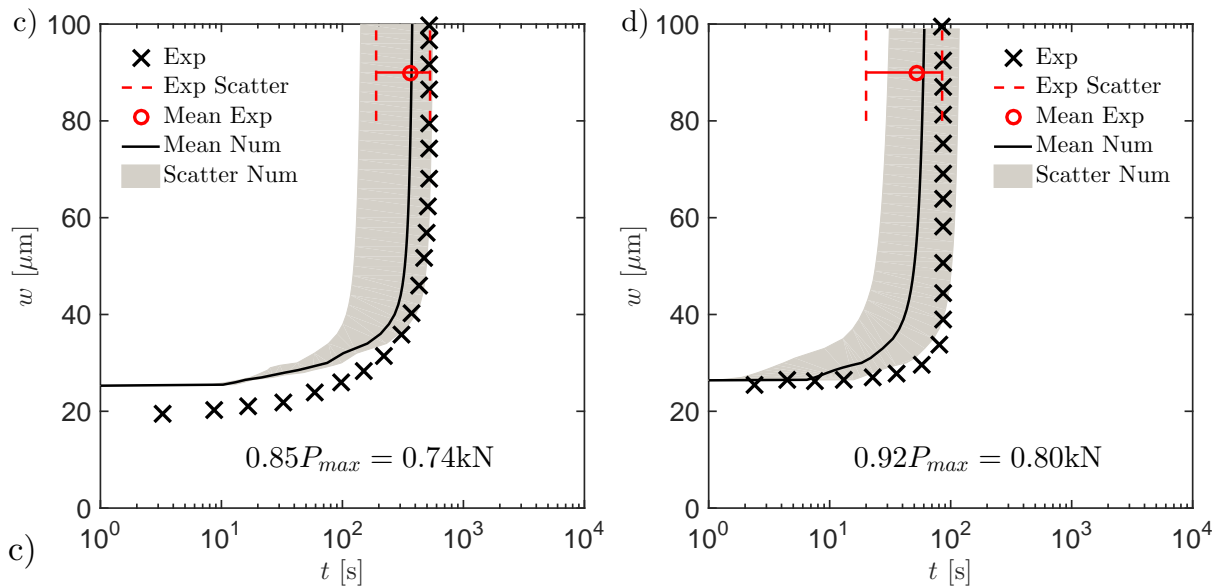

d)

Figure 8: Zhou's notched prism tests: Experimental and numerical crack opening vs. time curves for different load levels.

Figure 8 shows the crack opening-time curves for the different considered load levels. The solid lines represent the mean numerical crack opening evolution (mean of three repetitions), while the envelope illustrates their scatter. The simulations are compared to the one experimental curve per load level provided from Zhou [63, which is represented by the $\times$ markers. In all cases, the available curve is the one with the highest failure time among all the tests of a given 
load level. Additionally, Zhou also reported the experimental failure times for all tests. The vertical red dashed lines in Figure 8 denote the minimum and maximum experimental time to failure observed.

The comparison between the numerical and experimental results shows excellent agreement in terms of time to failure and related scatter for all the load levels. However, the numerical simulations yield a higher instantaneous crack opening with respect to the sole full experimental curve available. This fact may be considered of secondary importance since there are no information on the experimental scatter in that region, and because the times to failure are correctly estimated.

Additionally, also flexural creep tests on unnotched prisms were investigated based on the available experimental data. Specimens were loaded at 95, 90, $85,80,76,70$, and $67 \%$ of the reference load. The experimental value of the reference load, however, was not directly provided in Zhou's contribution. A loading rate of $50 \mathrm{~N} / \mathrm{s}$ was applied on four specimens which took around 40 seconds to fail. From these, a peak load of around $2 \mathrm{kN}$ can be calculated. The mean value of the numerically simulated related tests, which could serve as validation, was equal to $1.83 \mathrm{kN}$ and was used as reference load for the flexural creep study on unnotched prisms.
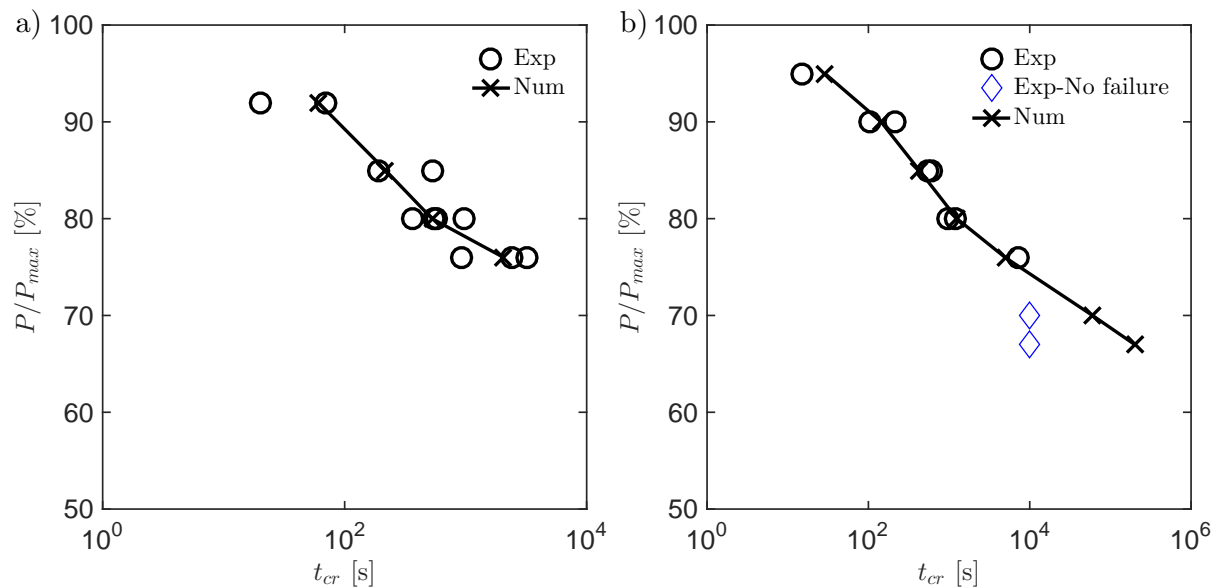

Figure 9: Experimental and numerical time to failure plots of flexural creep for a) notched, and b) unnotched specimens for Zhou's data 63. 
In Figure 9, numerical and experimental times to failure are plotted for the different load levels for both notched and unnotched prisms. The numerical results for both cases are in very good agreement with the measured data. In Figure $9 \mathrm{~b}$ the results of unnotched beams are shown. The diamond markers represent the tests which didn't fail within $10,000 \mathrm{~s}$ (2.78 hours). Nevertheless for these two load levels, which were 70 and $67 \%$, respectively, the failure times were numerically predicted as 17 hours and 2.3 days, respectively.

Furthermore, it is interesting to notice in Figure $9 \mathrm{a}$, for notched beams, the change of slope at the $76 \%$ load level. The slope is diverging from a typical power law that is assumed to describe the failure in relation to the load level [70. This is more pronounced in the case of the unnotched specimens (Figure 9p), where also lower load levels are involved. A more detailed analysis is given later on in this paper.
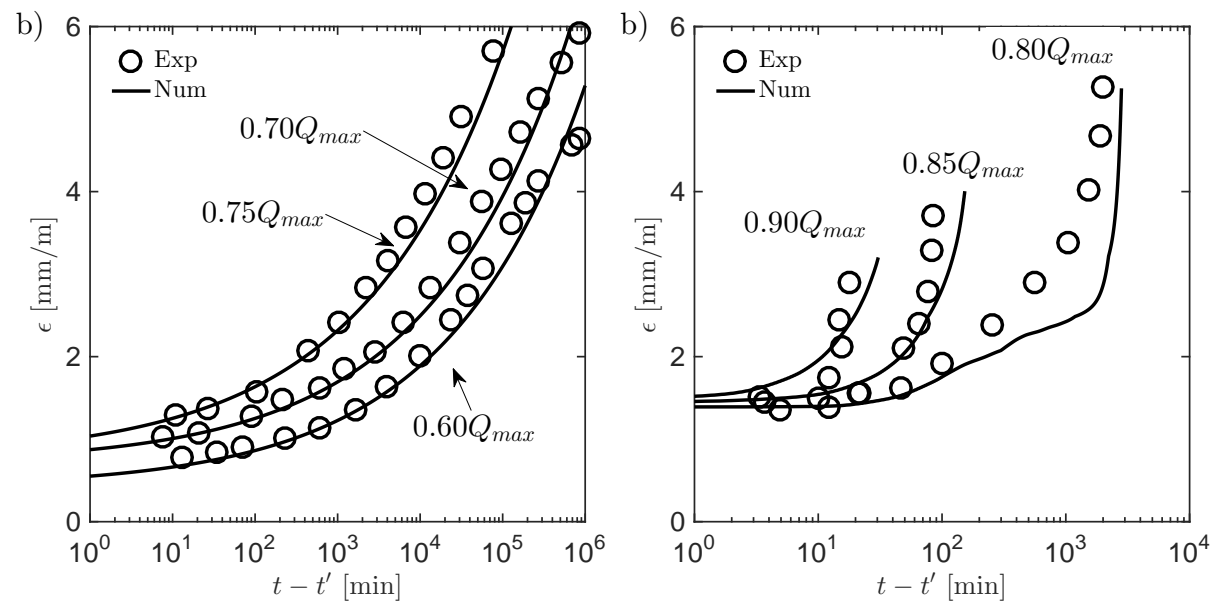

Figure 10: Sustained load validation results on specimens under compression loading: a) load levels that didn't lead to failure and b) load levels that led to failure.

The experimental results of Rüsch 62] are used for the sustained load validation performed on dog-bone-like specimens under compression at load levels of $60,70,75,80,85$, and $90 \%$ of the related quasi-static compressive strength $\left(Q_{\max }=517.11 \mathrm{kN} ; \sigma_{\max }=34.47 \mathrm{MPa}\right)$. In Figure 10 both the experimental and numerical sustained load results are shown. The 80, 85, and $90 \%$ load levels 
led to failure within the first 10,000 seconds, see Figure 10b, while the others didn't fail during the testing time as confirmed by the numerical simulations, see Figure 10
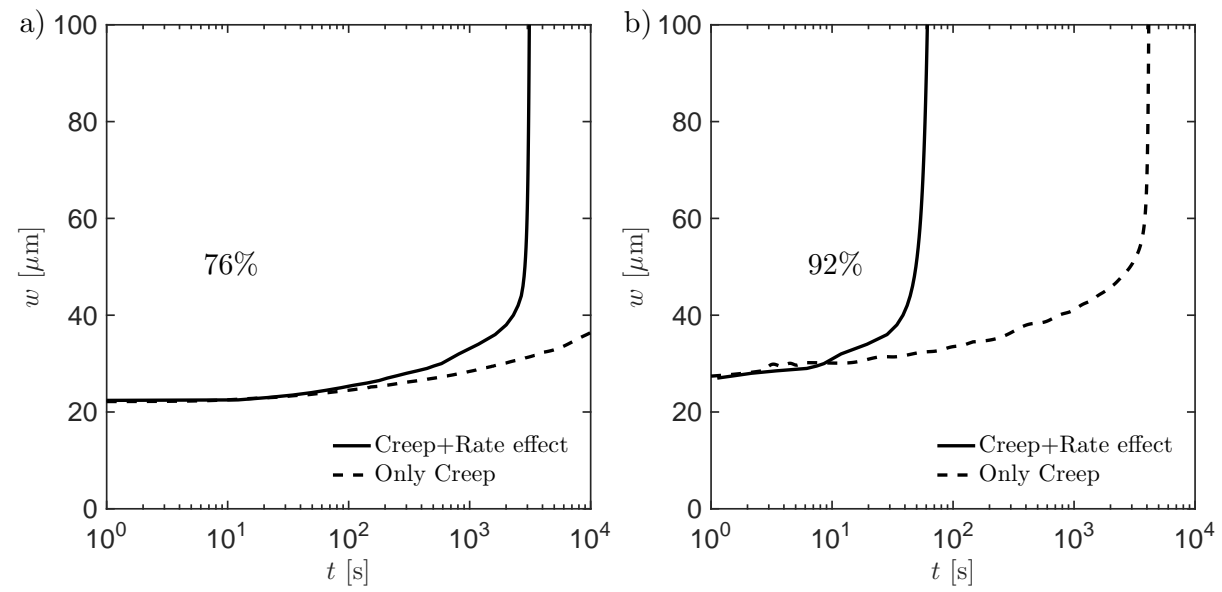

Figure 11: Crack opening time histories with and without the loading rate effect for load levels of a) $76 \%$, and b) $92 \%$.

\subsection{Creep vs. rate-dependent fracture}

It is also worth analyzing the role of the two different sources of time dependence: creep of the material and rate effect on crack opening. Therefore, a numerical study on time-dependent failure, just due to flexural creep, is performed.

In this case, sustained load simulations on unnotched specimens at 92 and $76 \%$ of the related quasi-static peak load are investigated. The aim of this analysis is to underline the importance of the loading rate dependency of the damage model on the time to failure prediction, i.e. tertiary creep. Figure 11 presents the crack width evolution in time for the two selected load levels. The numerical analysis considering only creep (dashed line) substantially deviates from the results of the full framework combining creep effects with rate-dependent fracture (solid line). For $76 \%$ of maximum load the creep-only simulation does not approach failure within the simulated time frame of 10,000 seconds. However, the full formulation predicts failure already after 3,000 seconds 111 a) in agree- 
ment with the experimental data. For $90 \%$ of the maximum load the creep-only simulation predicts a time-to-failure of two orders of magnitude greater than the one obtained by the full formulation $11 \mathrm{~b})$. These two examples demonstrate the importance of considering both sources of time-dependence for all load levels if concrete time-to-failure has to be predicted. Additionally, these

two examples highlight the importance of the rate-dependency of the damage model even for low load levels in which creep plays the major role concerning the time-dependent behavior and confirms what has been obtained in [17] using different numerical models.

\subsection{Structural time-to-failure}

Finally, it is worth performing a predictive study on the notched prisms of the Zhou's experimental investigation on load levels outside the range of tested values, i.e. 92 to $76 \%$. The motivation of this study can be found in the ongoing discussion on the allowable sustained load level to ensure the required life-time of 50 years. The main question concerns the equation that should be used to extrapolate from test results with reasonably quick failure times at high load levels to those at load levels that cause failure at common structural lifetimes, e.g. 50 years. Current proposals [71, 72, 73. suggest the use of a linear trend line in the logarithmic time scale as the long-term creep behavior would suggest. While there certainly is a range in which the logarithm of the failure times are increasing linearly with decreasing load level the response at very high or very low load levels most likely deviates from this trend. It is obvious that a sustained load can not exceed the quasi-static load capacity but only approach it with the asymptotic case of immediate failure (an infinitely short hold time), represented by an horizontal asymptote in a plot of logarithmic time for time that tends to zero. Similarly, the existence of a threshold load level can be postulated under which no damage develops and, thus, no failure can be expected, yielding a second horizontal asymptote for times that tend to infinity. This threshold may be found at the onset of apparent nonlinear viscoelasticity that is typically defined around $40 \%$ of the short-term strength for concrete. In 

the extrapolation model.

Experimentally it is very difficult to determine the expression of the function at high load levels due to scatter and the required temporal resolution. On the other side, it is practically impossible to measure the behavior at low load levels. The calibrated and validated computational framework, presented in this manuscript, provides the opportunity to study these cases numerically and, thus, gain important insights into this phenomenon.

In this contribution additional load levels of $98,95,72,70,65,60$, and $50 \%$ of the related quasi-static peak load, are simulated. The numerical simulation results with failure are indicated by $\times$ markers in Figure 12 while the available experimental results are marked by circles. The triangle denotes numerical run-through simulations that did not fail at the indicated time. The typical structural life-time of 50 years is marked as a vertical dashed line and the nodamage domain below $40 \%$ according to current codes as horizontal dashed line. as at load levels $\leq 76 \%$, confirming the postulated existence of two asymptotes that deviate from the linear trend in the intermediate domain.

If only the experimentally obtained data is considered and extrapolated using a linear trend line (red dashed line) hold times less than 10 seconds would 525 lead to analytically predicted load levels exceeding the short-term capacity. Furthermore, for a 50-year life-time a load level of not more than $20 \%$ would be admissible and even an unloaded structure would fail after about 3,200 years = $10^{11}$ seconds.

Considering the remarkable agreement between numerically predicted failure times and experiments the numerical results can serve as basis for the investigation of alternative yet still simple extrapolation models. As first approach, a bilinear fit is explored, (see blue solid line in Figure 12 ) which is describe by 

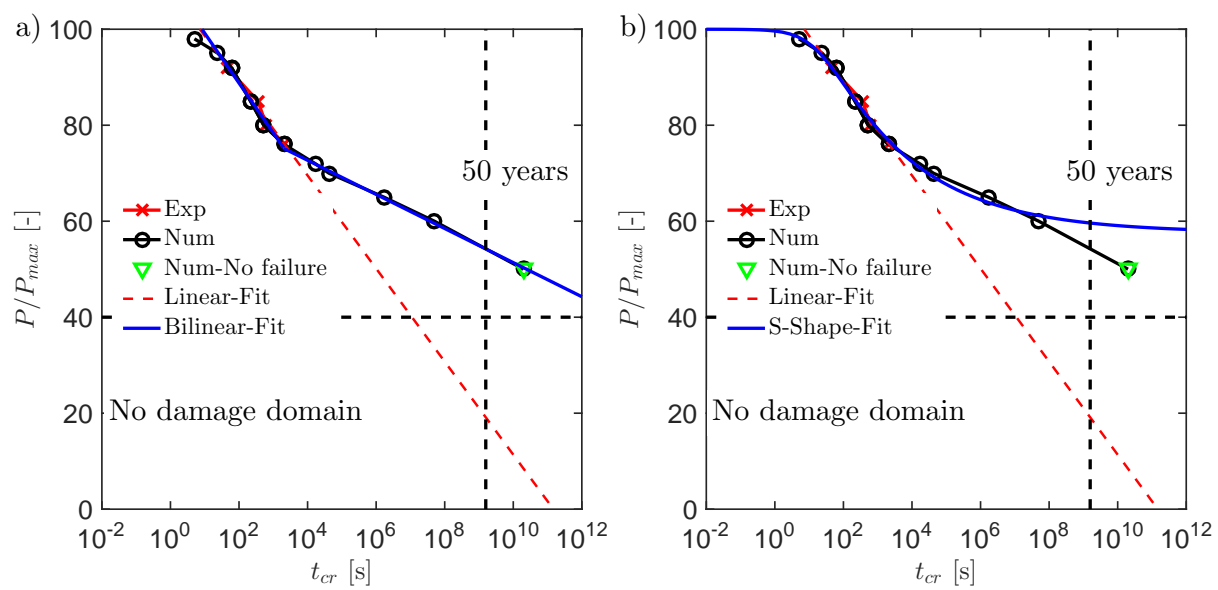

Figure 12: Numerical study of TTF and fitting approaches (a) bilinear (b) sigmoid function.

the Eq. 29

$$
P / P_{\max }= \begin{cases}-4.507 \cdot \ln \left(t_{c r}\right)+109.5, & P / P_{\max } \geq 76 \% \\ -1.543 \cdot \ln \left(t_{c r}\right)+86.91, & P / P_{\max }<76 \%\end{cases}
$$

This model still violates the two theoretical asymptotes but it is able to represent all practically relevant data (numerical and experimental). By fitting this type of function, a threshold load level at around $55 \%$ can be defined below which no failure within the lifetime (50 years) can be expected. However, the extrapolation theoretically still leads to failure also for very low load levels, although at very long times. Furthermore, the linear extrapolation to low load levels passes through the end point of the $50 \%$ load level simulation that had not yet failed at this point indicating a different functional form.

Alternatively, a function that has both asymptotes and exhibits a nearly linear intermediate domain in the range of typical loads is investigated. Compared to the bilinear model with 4 unknown fitting parameters a sigmoid function with 3 parameters can be introduced as

$$
\frac{P}{P_{\max }}=(1-a)+a \cdot\left(\frac{1}{1+b \cdot t_{c r}}\right)^{c}
$$

where $1-a=$ load level below which no failure occurs, $b$, and $c$ are the 
fitting parameters and $t_{c r}$ is the failure time.

The resulting optimum fit is presented as a solid blue line in Figure $12 \mathrm{~b}$, with fitted parameters $a=0.4239, b=0.0549$, and $c=0.1668$. The model perfectly predicts the transition from very high loads to loads around $70 \%$ and flattens out approaching a horizontal asymptote at $1-a=58 \%$. Even though the predicted simulation results can not be perfectly reproduced by the sigmoid model the approximation is reasonably close and consistent with the literature recommendations that suggest a maximum sustained load level of $50-60 \%$ for typical structural life-times [71, 72, 73, 74].

\section{Conclusions}

In this contribution the tertiary creep response of concrete has been successfully reproduced in a discrete element computational framework, both in tension and compression. The static parameters of the mechanical constitutive model

LDPM, creep parameters and rate parameters have been calibrated on two different data sets capturing the main concrete material and creep properties. A validation in terms of blind predictions was performed on time-to-failure tests, and on secondary creep data at various load levels showing excellent agreement with the experimental results. The main conclusions can be summarizes as follows:

- The time-dependent response of concrete under tensile (flexural) and compressive sustained loads can be modeled by linear visco-elasticity without distinction between compression and tension.

- The accurate prediction of failure times under sustained load requires the introduction of a rate-dependent damage model. In the proposed model this is achieved by scaling the tensile boundary based on the strain rate.

- The apparent macroscopic stress-dependence of creep (nonlinear creep) can be explained by a serial system of linear visco-elasticity and rate dependent damage model. The creep response of several tests with and with- 
out failure was successfully reproduced by the Micro-Prestress-Solidification Theory in combination with the rate-dependent Lattice Discrete Particle Model.

- Time-to-failure curves follow a sigmoid form in logarithmic time with two theoretical and numerically confirmed asymptotes: (i) a horizontal asymptote at $100 \%$ relative load; (ii) a terminal asymptote determined by the onset of damage development at infinite time.

\section{Acknowledgements}

The financial support by the Austrian Federal Ministry of Economy, Family and Youth and the National Foundation for Research, Technology and Development is gratefully acknowledged, as is the additional support by our industrial partners. The computational results presented have been achieved using the Vienna Scientific Cluster (VSC).

\section{References}

[1] CEN, Eurocode 2: Design of concrete structures - Part 1-1: General rules and rules for buildings, Vol. BS-EN-1992-1-1:2009, Eurpoean Committee for Standardization, 2009.

[2] ACI-209, Guide for Modeling and Calculating Shrinkage and Creep in Hardened Concrete, Tech. Rep. 209.2R-08, Farmington Hills (2008).

[3] Z. P. Bažant, Q. Yu, G.-H. Li, Excessive long-time deflections of prestressed box girders. i: Record-span bridge in palau and other paradigms, Journal of Structural Engineering 138 (6) (2012) 676-686. doi:10.1061/(ASCE) ST.1943-541X.0000487.

[4] Q. Yu, Z. P. Bažant, R. Wendner, Improved algorithm for efficient and realistic creep analysis of large creep-sensitive concrete structures, ACI Structural Journal 109 (5) (2012) 665-675. 
[5] Z. P. Bažant, Rate effects, size effects and nonlocal concept for fracture of concrete and other quasi-brittle material, in: Mechanisms of quasibrittle material, Dordrecht, The Netherlands, 1992, pp. 131-153.

[6] Z. P. Bažant, M. Jiràsek, R-curve modeling of rate and size effects in quasibrittle fracture, International Journal of Fracture 62 (4) (1993) 355-373. doi:10.1007/BF00017241.

[7] E. Hansen, A viscoelastic fictitious crack model, in: Proceedings Micromechanics of Quasibrittle Materials, 1992, pp. 156-165.

[8] F. P. Zhou, A. Hillerborg, Time-dependent fracture of concrete: testing and modelling, in: Proceedings Fracture Mechanics of Concrete Structures, The Netherlands, 1992, pp. 75-81.

[9] C. Zhang, B. Karihaloo, Stability of a crack in a linear viscoelastic tensionsoftening material, in: Proceedings Fracture Mechanics of Concrete Structures, The Netherlands, 1992, pp. 155-162.

[10] F. Barpi, S. Valente, Creep and fracture in concrete: a fractional order rate approach, Engineering Fracture Mechanics 70 (5) (2002) 611 - 623. doi:https://doi.org/10.1016/S0013-7944(02)00041-3

[11] S. Sathikumar, B. Karihaloo, S. Reid, A model for ageing visco-elastic tension softening material, Mechanics of Cohesive-frictional Materials 3 (1998) 27-39.

[12] R. De Borst, Smeared cracking, plasticity, creep, and thermal loadinga unified approach, Computer Methods in Applied Mechanics and Engineering

(4) 62 (1) (1987) 89 - 110. doi:https://doi.org/10.1016/0045-7825(87) 90091-0.

${ }_{620}$ [13] C. Mazzotti, M. Savoia, Nonlinear creep damage model for concrete under uniaxial compression, Journal of Engineering Mechanics 129 (2003) 10651075. 
[14] F. Benboudjema, F. Meftah, J. Torrenti, Interaction between drying, shrinkage, creep and cracking phenomena in concrete, Engineering Structures 27 (2) (2005) 239 - 250. doi:https://doi.org/10.1016/j. engstruct.2004.09.012.

[15] N. Challamel, C. Lanos, C. Casandjian, Creep damage modelling for quasi-brittle materials, European Journal of Mechanics - A/Solids 24 (4)

1 (2005) 593 -613. doi:https://doi.org/10.1016/j.euromechsol. 2005. 05.003

[16] G. van Zijl, R. Borst, G. J. Rots, A numerical model for the timedependent cracking of cementitious materials 52 (2001) $637-654$.

[17] G. Di Luzio, Numerical model for time-dependent fracturing of concrete, Journal of engineering mechanics 135 (7) (2009) 632-640.

[18] G. Cusatis, D. Pelessone, A. Mencarelli, Lattice Discrete Particle Model (LDPM) for failure behavior of concrete. I: Theory., Cement and Concrete Composites 33 (9) (2011) 881-890. doi:10.1016/j.cemconcomp. 2011.02. 011.

[19] G. Cusatis, A. Mencarelli, D. Pelessone, J. Baylot, Lattice Discrete Particle Model (LDPM) for failure behavior of concrete. II: Calibration and

4 validation, Cement and Concrete Composites 33 (9) (2011) 891-905. doi: $10.1016 /$ j.cemconcomp. 2011.02 .010

[20] Z. P. Bažant, A. B. Hauggaard, S. Baweja, F.-J. Ulm, Microprestresssolidification theory for concrete creep. i: Aging and drying effects, Journal of Engineering Mechanics 123 (11) (1997) 1188-1194.

[21] Z. P. Bažant, A. B. Hauggaard, S. Baweja, Microprestress-solidification theory for concrete creep. ii: Algorithm and verification, Journal of Engineering Mechanics 123 (11) (1997) 1195-1201. 
[22] G. Di Luzio, G. Cusatis, Hygro-thermo-chemical modeling of high performance concrete. i: Theory, Cement and Concrete Composites 31 (5) (2009) 301-308.

[23] G. Di Luzio, G. Cusatis, Hygro-thermo-chemical modeling of highperformance concrete. ii: Numerical implementation, calibration, and validation., Cement \& Concrete Composites 31 (2009) 309-324.

[24] M. Alnaggar, G. Cusatis, G. D. Luzio, Lattice discrete particle modeling (ldpm) of alkali silica reaction (asr) deterioration of concrete structures, Cement and Concrete Composites 41 (2013) 45 - 59. doi:https://doi. org/10.1016/j.cemconcomp.2013.04.015

[25] M. Abdellatef, M. Alnaggar, G. Boumakis, G. Cusatis, G. Di-Luzio, R. Wendner, Lattice discrete particle modeling for coupled concrete creep and shrinkage using the solidification microprestress theory, 2015, pp. 184193. doi:10.1061/9780784479346.022.

[26] I. Boumakis, M. Marcon, K. Ninčević, L.-M. Czernuschka, R. WanWendner, Concrete creep effect on bond stress in adhesive fastening systems, in: Proceedings of the 3rd International Symposium on Connections between Steel and Concrete, ConSC 2017, Stuttgart, Germany, 2017, pp. 396-406.

[27] I. Boumakis, M. Marcon, L. Wan, R. Wendner, Creep and shrinkage in fastening systems, in: CONCREEP 2015: Mechanics and Physics of Creep, Shrinkage, and Durability of Concrete and Concrete Structures - Proceedings of the 10th International Conference on Mechanics and Physics of Creep, Shrinkage, and Durability of Concrete and Concrete Structures, Vienna, Austria, 2015, pp. 657-666. doi:10.1061/9780784479346.079.

[28] I. Boumakis, M. Marcon, K. Ninčević, L. M. Czernuschka, R. Wan675 Wendner, Concrete creep and shrinkage effects on sustained load behavior of adhesive anchors, Enginnering and Structures (in review). 
[29] F.-J. Ulm, O. Coussy, Modeling of thermochemomechanical couplings of concrete at early ages, Journal of Engineering Mechanics 121 (7) (1995) 785-794. doi:10.1061/(ASCE)0733-9399(1995) 121:7(785).

[30] M. Cervera, J. Oliver, T. Prato, Thermo-chemo-mechanical model for concrete. i: Hydration and aging, Journal of Engineering Mechanics 125 (9) (1999) 1018-1027. doi:10.1061/(ASCE)0733-9399(1999)125:9(1018)

[31] A. M. Neville, Properties of concrete, 4th Edition, Pearson Education, 1963.

[32] J. Feng, W. Yao, W. Li, W. Li, Lattice discrete particle modeling of plain concrete perforation responses, International Journal of Impact Engineering 109 (2017) $39-51$.

[33] M. Marcon, J. Vorel, K. Ninčević, R. Wan-Wendner, Modeling adhesive anchors in a discrete element framework, Materials 10 (8).

[34] Z. P. Bažant, M. R. Tabbara, M. T. Kazemi, G. Pijaudier-Cabot, Random particle model for fracture of aggregate or fiber composites., Journal of Engineering Mechanics 116 (8) (1990) 1686-1705.

[35] G. Cusatis, Z. P. Bažant, L. Cedolin, Confinement-shear lattice model for concrete damage in tension and compression: I. theory, Journal of Engineering Mechanics 129 (2003) 1439-1448.

[36] G. Cusatis, E. Schauffert, Discontinuous cell method (DCM) for cohesive fracture propagation, in: Proceedings of the 7th international conference on fracture mechanics of concrete and concrete structures (FraMCos 7), (Jeju, South Korea), Korea Concrete Institute, 2010, pp. 23-28.

[37] G. Cusatis, X. Zhou, High-order microplane theory for quasi-brittle materials with multiple characteristic lengths, Journal of Engineering Mechanics 140 (7). doi:10.1061/(ASCE) EM.1943-7889.0000747.

[38] R. Rezakhani, G. Cusatis, Generalized mathematical homogenization of the lattice discrete particle model, in: Proceedings of the 8th International 
Conference on Fracture Mechanics of Concrete and Concrete Structures, FraMCoS 2013, Toledo, Spain, 2013, pp. 261-271.

[39] Z. P. Bažant, S. Baweja, Creep and shrinkage prediction model for analysis and design of concrete structures - model B3, Matériaux et constructions 28 (180) (1995) 357-365.

[40] N. Gardner, M. Lockman, Design provisions for drying shrinkage and creep of normal-strength concrete, ACI Materials Journal 98 (2) (2001) 159-167.

[41] R. Wendner, M. H. Hubler, Z. P. Bažant, Statistical justification of model B4 for multi-decade concrete creep using laboratory and bridge databases and comparisons to other models, Materials and Structures 48 (4) (2015) 815-833. doi:10.1617/s11527-014-0486-1

[42] M. Hubler, R. Wendner, Z. P. Bažant, Statistical justification of model b4 for drying and autogenous shrinkage of concrete and comparisons to other 口 models, Materials and Structures 48 (4) (2015) 797-814. doi:10.1617/ s11527-014-0516-z.

[43] R. Wendner, M. Hubler, Z. P. Bažant, Optimization method, choice of form and uncertainty quantification of model b4 using laboratory and multidecade bridge databases, Materials and Structures/Materiaux et Constructions 48 (4) (2015) 771-796. doi:10.1617/s11527-014-0515-0.

[44] Z. P. Bažant, S. T. Wu, Rate-type creep law of aging concrete based on maxwell chain, Materials and Structures/Materiaux et Constructions 7 (1) (1974) 45-60. doi:10.1007/BF02482679.

[45] M. Alnaggar, G. Di Luzio, G. Cusatis, Modeling time-dependent behavior of concrete affected by alkali silica reaction in variable environmental conditions, Materials 10 (5). doi:10.3390/ma10050471.

[46] G. Di Luzio, G. Cusatis, Solidification-microprestressmicroplane (SMM) theory for concrete at early age: Theory, validation and application., 
International Journal of Solids and Structures 50 (6) (2013) 957-975. doi:10.1016/j.ijsolstr.2012.11.022.

[47] L. Wan, R. Wendner, B. Liang, G. Cusatis, Analysis of the behavior of ultra high performance concrete at early age, Cement and Concrete Composites 74 (2016) 120-135.

[48] L. Wan-Wendner, R. Wan-Wendner, G. Cusatis, Age-dependent size effect and fracture characteristics of ultra-high performance concrete, Cement and Concrete Composites 85 (Supplement C) (2018) 67 - 82. doi:https: //doi.org/10.1016/j.cemconcomp.2017.09.010

[49] R. Wendner, K. Ninčević, I. Boumakis, L. Wan, Age-dependent lattice discrete particle model for quasi-static simulations, Key Engineering Materials 711 (1) (2016) 1090-1097.

[50] Z. P. Bažant, Y. Xi, Continuous retardation spectrum for solidification theory of concrete creep, Journal of Engineering Mechanics - ASCE 121 (2) (1995) 281-288.

[51] Z. P. Bažant, G. Cusatis, L. Cedolin, Temperature effect on concrete creep modeled by microprestress- solidification theory, Journal of Engineering Mechanics 130 (6) (2004) 691-699.

[52] D. Watstein, Effect of straining rate on the compressive strength and elastic properties of concrete, ACI Journal 49 (4).

[53] B. P. Hughes, R. Gregory, Concrete subjected to high rates of loading in compression, Magazine of Concrete Research 24 (78) (1972) 25-36. doi: $10.1680 / \mathrm{macr} .1972 .24 .78 .25$.

[54] J.-H. Yon, N. M. Hawkins, A. S. Kobayashi, Strain-rate sensitivity of concrete mechanical properties, ACI Materials Journal 89 (2).

[55] H. W. Reinhardt, Strain rate effects on the tensile strength of concrete as predicted by thermodynamic and fracture mechanics models, MRS Proceedings 64 (1985) 1. doi:10.1557/PROC-64-1. 
[56] R. J. Mainstone, Properties of materials at high rates of straining or loading, Matériaux et Construction 8 (2) (1975) 102-116. doi:10.1007/ BF02476328.

[57] W. H. Dilger, R. Koch, R. Kowalczyk, Ductility of plain and confined concrete under different strain rates, ACI Journal 81 (1).

[58] P. H. Bischoff, S. H. Perry, Compressive behaviour of concrete at high strain rates, Materials and Structures 24 (6) (1991) 425-450. doi:10. 1007/BF02472016.

[59] J. Smith, G. Cusatis, Numerical analysis of projectile penetration and perforation of plain and fiber reinforced concrete slabs, International Journal for Numerical and Analytical Methods in Geomechanics 41 (3) (2016) 315337. doi:10.1002/nag.2555

[60] Z. P. Bažant, Creep and damage in concrete, in: Proceedings, 4th Materials Science of Concrete, Westerville, Ohio, 1995, pp. 355-389.

[61] Z. S. Wu, Z. P. Bažant, Finite element modeling of rate effect in concrete fracture with influence of creep, in: Creep and Shrinkage of concrete, Proceedings of the 5th International RILEM symposium, Barcelona, Spain, 1993, pp. 427-432. doi:10.1061/9780784479346.079.

[62] H. Rüsch, Researches toward a general flexural theory for structural concrete, ACI Journal 57 (1960) 1-28.

[63] F. P. Zhou, Time-dependent crack growth and fracture in concrete, Dissertation, Lund Univeristy of Technology, Lund, Sweden (1992).

[64] A. Hillerborg, The theoretical basis of a method to determine the fracture energy $G_{F}$ of concrete, Materials and Structures 18 (4) (1985) 291-296. doi:10.1007/BF02472919.

[65] J. Podroužek, J. Vorel, I. Boumakis, G. Cusatis, R. Wan-Wendner, Implications of spatial variability characterization in discrete particle models, 
in: 9th International Conference on Fracture Mechanics of Concrete and Concrete Structures (FraMCos 9), Berkeley, CA, USA, 2016.

[66] M. Marcon, J. Podroužek, J. Vorel, R. Wan-Wendner, Characterisation of spatial variability in lattice models, Enginnering and Structures (in review).

[67] fib, Code-type models for concrete behaviour, Background of MC2010, no. 70 in fib Bulletin, fédération internationale du béton, 2013.

[68] G. D. Luzio, G. Muciaccia, L. Biolzi, Size effect in thermally damaged concrete, International Journal of Damage Mechanics 19 (5) (2010) 631656. doi:10.1177/1056789509338320.

[69] G. D. Luzio, L. Biolzi, Assessing the residual fracture properties of thermally damaged high strength concrete, Mechanics of Materials 64 (2013) $27-43$.

[70] H. W. Reinhardt, Loading rate, temperature, and humidity effects, in: Fracture Mechanics of Concrete: test method., RILEM 89-FMT, 1992.

[71] P. L. Domone, Uniaxial tensile creep and failure of concrete, Magazine of Concrete Research 26 (88) (1974) 144-152. doi:10.1680/macr.1974.26. 88.144

[72] M. A. Al-Kubaisy, A. G. Young, Failure of concrete under sustained tension, (1) Magazine of Concrete Research 27 (92) (1975) 171-178. doi:10.1680/ macr.1975.27.92.171

[73] H. W. Reinhardt, Sustained tensile tests on concrete (in german), in: Baustoff 85, Bauverlag, Wiesbaden, 1985.

[74] A. Carpinteri, S. Valente, F. P. Zhou, G. Ferrara, G. Melchiorri, Tensile and flexural creep rupture tests on partially-damaged concrete specimens 30 (1997) 269-276. 